\title{
Association between regional summer monsoon onset in South Asia and Tibetan Plateau thermal forcing
}

\author{
Die $\mathrm{Hu}^{1,2} \cdot$ Anmin Duan ${ }^{1,2,3} \cdot$ Ping Zhang ${ }^{1,2}$
}

Received: 8 April 2021 / Accepted: 25 January 2022 / Published online: 21 February 2022

(c) The Author(s) 2022

\begin{abstract}
By using multiple data sources and numerical simulation results from the atmospheric general circulation model (AGCM) of CAM4.0 (Community Atmosphere Model, version 4), we investigated the effect of thermal forcing over the Tibetan Plateau (TP) on the onset of the summer monsoon in the Arabian Sea (AS) and India. Results indicate that the spatial distribution of diabatic heating over the TP in May is a southeastern-northwestern inverse pattern. This diabatic heating shows a robust negative relationship with the onset date of the summer monsoon over the AS and India. A positive diabatic heating seesaw pattern can enhance the ascending (descending) motion over the southeastern (northwestern) TP, corresponding to above (below) normal in- situ precipitation. Temperature budget diagnosis reveals that the adiabatic heating due to anomalous vertical motion and relevant horizontal advection of temperature in the mid-upper troposphere are responsible for the warming over the TP. Consequently, the reversal of the meridional temperature gradient from winter to summer over South Asian regions occurs earlier than the climate-mean state. Furthermore, the diabatic heating over the TP induces an enhanced and westward-extended South Asian High (SAH), which together with the easterly along the southern flank of the SAH superimpose on the low-level westerly flow over the AS and India, results in intensive upper-level divergence-pumping and upward motion. This anomalous circulation configuration in lower and upper levels further facilitates an earlier onset of the summer monsoon in AS and India. These findings are corroborated in the sensitivity runs based on CAM4.0.
\end{abstract}

Keywords Tibetan Plateau · Thermal forcing $\cdot$ South Asian summer monsoon · Onset

\section{Introduction}

The onset of the summer monsoon usually signals the seasonal transition from winter to summer in the Northern Hemisphere, characterized by the onset of the rainy season, large-scale convection, and abrupt transitions of largescale atmospheric circulation (Taniguchi and Koike 2006). An advanced or delayed start of the summer monsoon have

Anmin Duan

amduan@lasg.iap.ac.cn

$1 \quad$ State Key Laboratory of Numerical Modeling for Atmospheric Sciences and Geophysical Fluid Dynamics, Institute of Atmospheric Physics, Chinese Academy of Sciences, Beijing 100029, China

2 College of Earth Science, University of Chinese Academy of Sciences, Beijing 100049, China

3 State Key Laboratory of Marine Environmental Science, College of Ocean and Earth Sciences, Xiamen University, Xiamen 361102, China severe impacts on agriculture (e.g., crop selection, planting, irrigation) and seriously affect a substantial fraction of the world's population. As a key component of the Asian-Australian summer monsoon system, the South Asian summer monsoon (SASM), including the summer monsoon over the Bay of Bengal (BOB), Arabian Sea (AS), and India, is closely related to the occurrence of droughts and floods in the southern Indian Peninsula, Indochina Peninsula, and some regions in China (Liu and Ding 2008; Tao and Chen 1987; Xing et al. 2015).

In South Asia, there are two maximum summer rainfall areas: the central BOB and the southeastern AS (Wang and Ho 2002). The SASM first begins in the BOB in early May (Wang and Ho 2002; Wu and Zhang 1998; Xing et al. 2015; Yu et al. 2020; Zhang et al. 2017), and the BOB leads the monsoon onset over the AS and India by about one month because of the 'monsoon onset barrier' (Liu et al. 2014a). In late May, significant precipitation is observed over the southern AS near the equator, gradually spreading to most parts of the AS (Abe et al. 2013; Aneesh and Sijikumar 
2020; Kajikawa et al. 2012). Around the beginning of June, the monsoon convection reaches the southernmost tip of the Indian Peninsula (in Kerala), and thus the Indian summer monsoon breaks out (Aneesh and Sijikumar 2020; Pai and Rajeevan 2009). Once the Indian summer monsoon has established in Kerala, this marks the full start of the SASM, whereupon abundant vapor is transported from the AS and BOB to eastern China (Liu 2013; Zhang 2001).

The onset of the SASM shows significant interannual variability, and it is modulated by many factors. For instance, following warm El Niño-Southern Oscillation (ENSO) events (El Niño), the breakout of the summer monsoon over the South Asian regions is usually postponed, while following cold ENSO events (La Niña), the SASM onset tends to advance (Liu et al. 2014b; Neena et al. 2020; Sun et al. 2017; Xavier et al. 2007). ENSO can efficiently modulate the onset dates of the SASM through regulating the sea surface temperature (SST) anomalies in tropical oceans (Liu et al. 2014b), the Walker circulation (Mao and Wu 2006; Meng and Wu 2000; Webster and Yang 1992), and the ENSOinduced 'atmospheric-bridge' (Sun et al. 2017). Neena et al. (2020) demonstrated that the El Niño in boreal spring can support two distinct eastward waveguides from the central and eastern Pacific to the SASM region, thus inducing Rossby waves to modulate the thermal structure over the SASM region in May and lead to a delayed monsoon onset. Besides, the seasonal evolution and variation of the South Asian High (SAH) play an important role in the development of the monsoon onset vortex, which is closely related to the onset of the SASM (Liu et al. 2013; Wu et al. 2010). The upper-level divergence and the easterly along the southern flank of the SAH, together with the lower-level southwesterly, form the summer circulation structure in SASM regions (Wei et al. 2019). The intensity and location of the SAH strongly depends on the diabatic heating over the Tibetan Plateau (TP) (Wu et al. 2015, 2007).

Generally, previous studies have mainly attributed the substantial interannual variation of the SASM onset to the following factors: (1) the arrival of a wet phase of a low-frequency intraseasonal oscillation and Madden-Julian Oscillation (Taraphdar et al. 2018); (2) the seasonal northward movement of the Intertropical Convergence Zone (Saha and Saha, 1980); (3) the generation of monsoon onset vortexes over the BOB and AS; (4) the role of SST anomalies and air-sea interactions, i.e., the AS warm pool, ENSO (Liu et al. 2014b; Mao and Wu 2006; Vinayachandran et al. 2007); (5) the establishment of the timing of the SAH over the Indochina Peninsula (Liu et al. 2013; Wei et al. 2014; Wu et al. 2015); and (6) the mechanical and thermal effects of the TP (Mao and Wu 2006; Wu and Zhang 1998). Among these factors, the influence of the TP has been consistently and continually emphasized by researchers (Abe et al. 2013;
Boos and Kuang 2010; Duan et al. 2020; Liu et al. 2020; Wu et al. 2015; Yu et al. 2020).

The thermal effects of the TP on the SASM onset mainly include an increase of the land-sea thermal contrast by heating the mid-upper troposphere and the resultant strengthening of the surrounding atmospheric circulation. Strong spring surface sensible heating over the central-western TP contributes to an early onset of the Indian summer monsoon through increasing the land-sea thermal contrast (Zhang et al. 2015), while a positive (negative) surface sensible heating anomaly over the southern (northern) TP leads to a delay (advancement) of the SASM by weakening (enhances) the cross-equatorial flow to the AS and BOB (Yu et al. 2020). However, previous studies have focused mainly on the effect of the TP on the large-scale onset of the whole SASM region, and it is necessary to reveal the potential contribution from the TP thermal forcing on the monsoon onset in individual subregions such as the BOB, AS, and India. In this work, we aim to address the following three questions: (1) whether there is a significant linkage of monsoon onsets between the three subregions of the SASM; (2) whether there is a relationship between TP thermal forcing and the monsoon onset in the three subregions of the SASM; and (3) how the thermal forcing over the TP influences the onset of the SASM.

The remaining of the paper is arranged as follows. The data, methods and model employed in this study are briefly described in Sect. 2. Section 3 presents the climatological features of the onset of the SASM, and then in Sect. 4 the connections between the onset dates of each subregion of the SASM and the thermal forcing over the TP are investigated. Then, in Sect. 5, the physical mechanism is investigated using the results from an atmospheric general circulation model CAM4.0. And finally, a summary and discussion are presented in Sect. 6.

\section{Data and methods}

\subsection{Data}

The datasets employed in this study are as follows:

(1) The daily atmospheric data (wind, temperature, specific humidity, and heating rates) during 1979-2016 were obtained from the Japan Meteorological Agency Japanese 55-year Reanalysis (JRA-55) dataset with a horizontal resolution of $1.25^{\circ} \times 1.25^{\circ}$ (Kobayashi et al. 2015) at https://jra.kishou.go.jp/JRA-55/index_en. $\mathrm{html} \#$ jra-55. The daily heating rate data include heating rates of large-scale condensation, convection, vertical diffusion, longwave radiation, and solar radiation. 
(2) The daily surface sensible heat flux and the latent heat release of condensation via precipitation over the TP at 80 routine weather stations for the period 1979-2016, and the total atmospheric diabatic heating $(E)$ over the TP for the period 1984-2015, were obtained from Duan et al. (2018). Note that the diurnal variation in the bulk transfer heat coefficient was obtained by the sensible heat flux algorithm proposed by Yang et al. (2009). E comprises three components: surface sensible heat flux, latent heat release of condensation and radiation flux. The calculation of $E$ is named the direct computational method (Ye and Gao 1979), which has been adopted in many studies (e.g., Chen et al. 1985; Duan et al. 2018; Wang et al. 2011). Comparing with the reverse computational method of estimating the atmospheric diabatic heating over the TP (Luo and Yanai 1984; Yanai et al. 1973), $E$ can avoid the errors caused by the uncertainty of vertical velocity in different reanalysis data. The expression of $E$ is as follows:

$$
E=\mathrm{SH}+\mathrm{LH}+\mathrm{NR},
$$

where $\mathrm{SH}$, and $\mathrm{LH}$ represent the local surface sensible heat and latent heat, respectively. NR represents the net radiation flux of the air column. NR can be obtained by the net radiation values measured at the top of atmosphere and at the surface. The formula is as the follows:

$\boldsymbol{N R}=\boldsymbol{R}_{\infty}-\boldsymbol{R}_{0}=\left(\boldsymbol{S}_{\infty}^{\downarrow}-\boldsymbol{S}_{\infty}^{\uparrow}\right)-\left(\boldsymbol{S}_{0}^{\downarrow}-\boldsymbol{S}_{0}^{\uparrow}\right)-\left(\boldsymbol{F}_{0}^{\downarrow}-\boldsymbol{F}_{0}^{\uparrow}\right)-\boldsymbol{F}_{\infty}$,

Where $\boldsymbol{R}_{\infty}$ and $\boldsymbol{R}_{0}$ are the net radiation values measured at the top of atmosphere and at the surface. S and F represent the shortwave and longwave radiation flux. The superscripts $\downarrow$ and $\uparrow$ represent downward and upward transport of the radiation flux, and the subscripts 0 and $\infty$ represent the radiation flux at the surface and at the top of atmosphere, respectively. More details about the calculation of SH, LH and NR are given by Duan et al. (2018) and Zhao et al. (2018).

The 80 routine weather stations over the TP are mainly distributed in the central and eastern TP, with only three stations in the western TP (Fig. 1a). The complex terrain and harsh living conditions limit the distribution of observation stations, especially over the western TP. Previous studies have shown that JRA-55 performs well in estimating the atmospheric heat source over the TP (Liu and He 2015; Wang et al. 2018; Zhu 2012). Therefore, JRA-55 reanalysis datasets are adopted to represent the heating effect over the TP. The expression of atmospheric diabatic heating based on JRA-55 datasets (E_JRA55) is as follows:

$$
\begin{aligned}
E_{\mathrm{JRA} 55}= & \int_{P_{s}}^{P t}(\mathrm{VDFHR}+\mathrm{LRGHR}+\mathrm{CNVHR} \\
& +\mathrm{LWHR}+\mathrm{SWHR}) d_{P},
\end{aligned}
$$

where $P$ is the air pressure, the limits of integration used here $\left(P_{s}=1000 \mathrm{hPa}\right.$ and $\left.P_{t}=100 \mathrm{hPa}\right)$ represent the approximate depth of the free troposphere, VDFHR denotes the sensible heat, the sum of CNVHR and LRGHR represents the latent heat release due to condensation, and the sum of LWHR and SWHR represents the net radiation of the air column.

The atmospheric diabatic heating $(E)$ based on JRA-55 datasets can represent well the spatial distribution and temporal variation of the observed datasets over the TP in May- that is, the atmospheric heating over the TP gradually decreases from the southeastern TP to the northwestern TP, and the diabatic heating over the western TP is relatively weak. Although the $E$ over the TP based on JRA-55 datasets is generally stronger than that in the observation, the correlation coefficient between them is 0.65 (statistically significant at the $99 \%$ confidence level) (Fig. 1c). In addition, the temporal variations of $E$ and latent heat over the TP in May exhibit close consistency and both show opposite variations to the sensible heat. This may indicate that the relative importance of sensible heat in the atmospheric diabatic heating decreases as the latent heat gradually becomes more dominant in May (Zhao et al. 2018).

(3) Monthly SST data were obtained from the Extended Reconstructed SST dataset, version 5 (ERSST.v5), with a resolution of $2^{\circ} \times 2^{\circ}$ over the period 1978-2016 (Huang et al. 2017) (https://psl.noaa.gov/data/gridded/ data.noaa.ersst.v5.html).

(4) Other fields used in this study include the National Oceanic and Atmospheric Administration (NOAA) daily interpolated outgoing longwave radiation (OLR), with a $2.5^{\circ} \times 2.5^{\circ}$ resolution, obtained from the National Center for Atmospheric Research (NCAR) archives (1979-2016) (Liebmann and Smith 1996) (https:// www.psl.noaa.gov/cgibin/db_search/DBSearch.pl? Dataset $=$ NOAA+Interpolated + OLR $\&$ Variable $=$ Outgo ing+Longwave+Radiation), and pentad precipitation on $2.5^{\circ} \times 2.5^{\circ}$ grids during $1979-2016$ from the Climate Prediction Center Merged Analysis (CMAP) Xie and Arkin 2021) (https://www.psl.noaa.gov/data/gridd ed/data.cmap.html).

Statistical methods, such as linear regression, empirical orthogonal function (EOF) analysis, composite analysis, Pearson correlation, and partial correlation analysis, were utilized. EOF, linear regression and correlation analysis were performed with detrended data in this study. The Student's $t$-test was adopted to evaluate the statistical significance of composite and linear regression analysis. The pentad dataset in this study consists of 73 pentads per year, with the 12th pentad from February 25 to March 1 regardless of whether it was a leap year. 

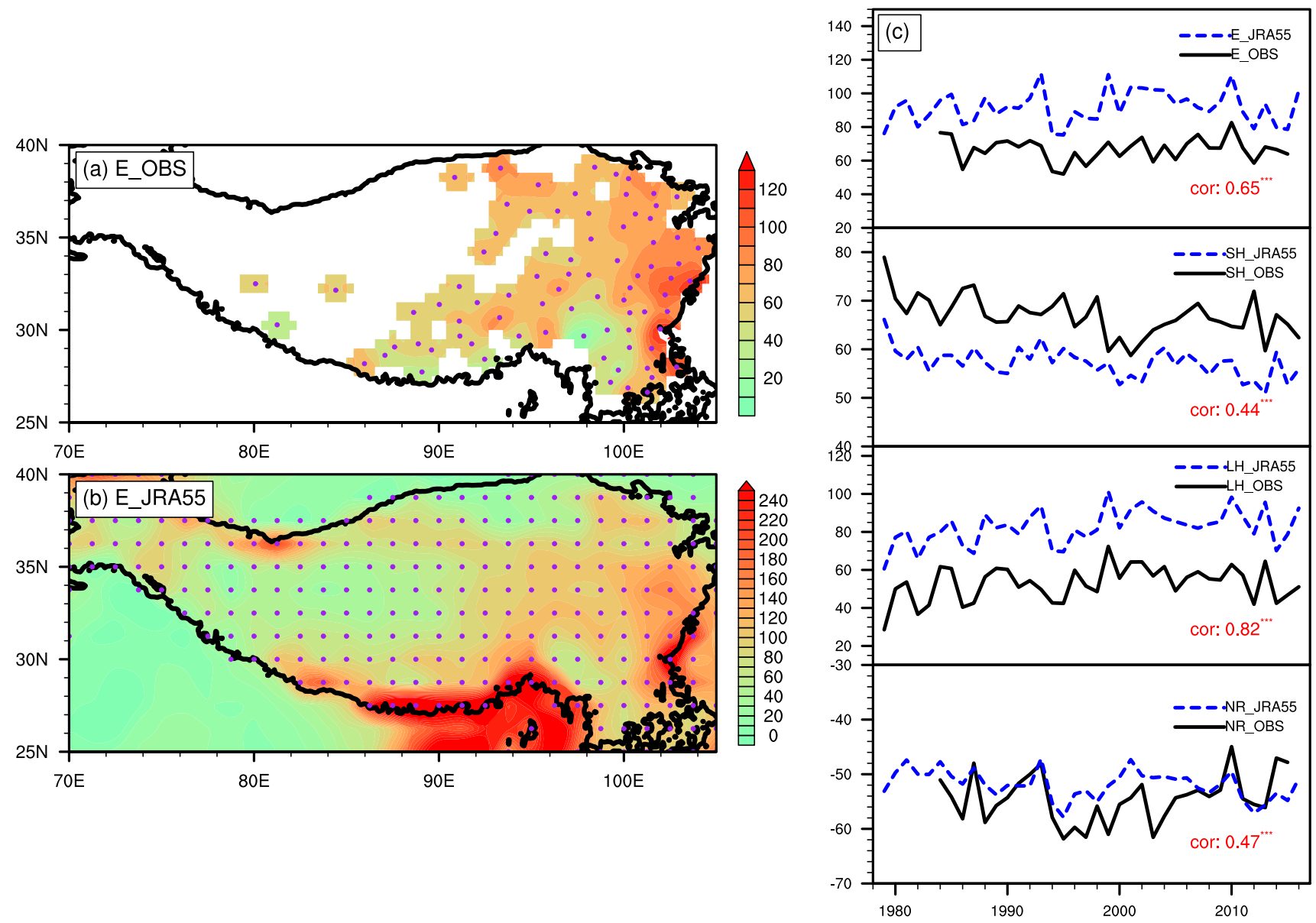

Fig. 1 Climatological spatial patterns based on a observed datasets and b JRA-55 datasets and time series $\mathbf{c}$ of the atmospheric heat source/sink (E), sensible heat $(\mathrm{SH})$, latent heat $(\mathrm{LH})$ and net radiation (NR) over the TP in May. The purple dots in $\mathbf{a}$ and $\mathbf{b}$ represent the distribution of the 80 routine weather stations and TP areas with an altitude $>2000 \mathrm{~m}$, respectively. The solid black curves in c denote the 80-station averaged $\mathrm{E}, \mathrm{SH}, \mathrm{LH}$ and $\mathrm{NR}$ based on the observed data-

\subsection{Model}

This study adopted the Community Atmosphere Model, version 4 (CAM4.0; Gent et al. 2011), which is the atmospheric component of the Community Earth System Model, version 1.2.0 (CESM1.2.0; Hurrell et al. 2013) developed by NCAR (http://www.cesm.ucar.edu/models/cesm1.2/). CAM4.0 includes moderate changes in model configurations compared to CAM3, and one of the most important ones is the change from the spectral core used in CAM3.0 to the finitevolume dynamical core used in CAM4.0 (Neale et al. 2010), which exhibits great improvements in simulating climate mean states (Hurrell et al. 2013). The f19_g16 configuration, with a horizontal resolution of approximately $2^{\circ}\left(1.9^{\circ} \times 2.5^{\circ}\right)$ for the atmospheric model with the "F_2000" component, was selected. The control run (CTRL) was forced by the climatological annual cycle of SST with the fixed external sets, and the blue dotted curve denotes the dot areas' averaged E, SH, LH and NR based on JRA-55 in $\mathbf{b}$, and the correlation coefficients between them are marked in the third panel. The black contours in a and $\mathbf{b}$ indicate the $2000 \mathrm{~m}$ topographic height. Statistical significance is shown by asterisks: $* p<0.1, * * p<0.05$ and $* * * p<0.01$ (the same hereafter)

forcing (greenhouse gases, aerosols, volcanic activity and solar activity) at the year-2000 level. The CTRL run was integrated for 17 model years, and the first dates of the last 15 years were adopted to provide the initial conditions for the two subsequent sensitivity runs.

In order to investigate the effect of the seesaw pattern of diabatic heating over the TP, the sensitivity experiments are designed as follows. We mainly changed the vertical profiles of diabatic heating due to convection over the eastern TP region $\left(20^{\circ}-40^{\circ} \mathrm{N}, 85^{\circ}-105^{\circ} \mathrm{E}\right)$ (Fig. $\left.2 \mathrm{a}\right)$ in the two sensitivity runs because the significant abnormal signals of diabatic heating are over the eastern and southeastern TP (Fig. 2), and the strong diabatic heating over the eastern TP associated with precipitation dominates in May. Furthermore, the vertical profile of diabatic heating due to convection over the eastern TP region above $1500 \mathrm{~m}$ in May was set to 0.5 and 1.5 times the normal based on the CTRL run in the 
Fig. 2 a The heating area (green meshed shading; $20^{\circ}-40^{\circ} \mathrm{N}$, $\left.85^{\circ}-105^{\circ} \mathrm{E}\right)$ over the Tibetan Plateau $(>1500 \mathrm{~m})$ in the sensitivity runs. b, $\mathbf{c}$ Vertical profile of temperature tendency due to convection (units: $\mathrm{K} \mathrm{day}^{-1}$ ) averaged over the areas in $\mathbf{a}$ based on b JRA-55 datasets (the black, purple and green lines represent the climatological mean value, the strongest value, and the weakest value during 1979-2016), respectively, and c model simulation (the black, purple and green lines represent the CTRL value, the strong sensitivity experiment value (EXN_POS), and the weak sensitivity experiment value (EXN_NEG)). The red contours indicate the $2000 \mathrm{~m}$ topographic meters

(a) TP area in CAM4.0

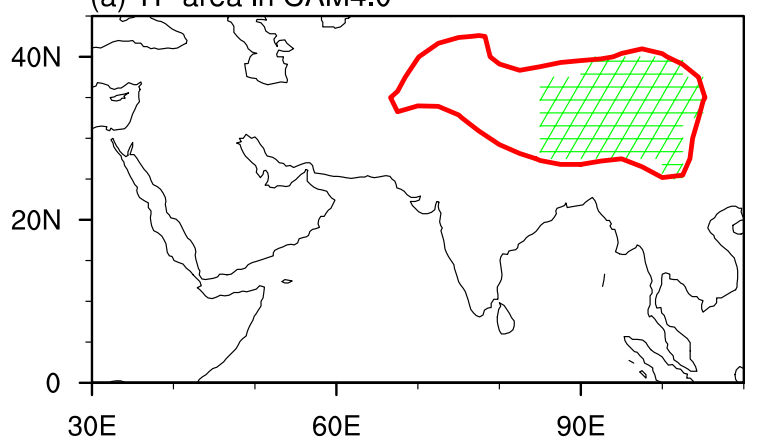

(b) JRA55

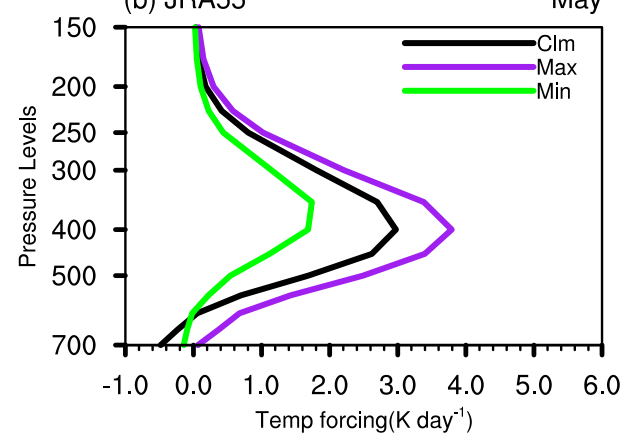

(c) CAM4.0

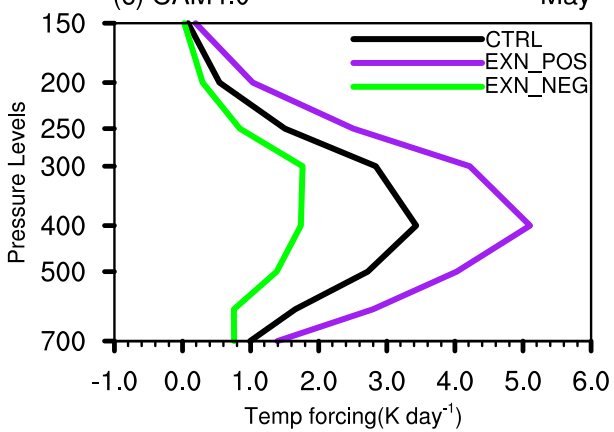

negative (EXP_NEG) and positive (EXP_POS) sensitivity experiments, respectively (Fig. 2c). This is because the main anomalies are concentrated in the middle troposphere (300-600 hPa), and the strongest and weakest vertical profiles of diabatic heating due to convection over the TP are approximately $0.5-1.5$ times to the climate mean state in reanalysis data (Fig. 2b). Similar experimental designs were adopted in Sun et al. (2019) and Zhao et al. (2021). Each sensitivity experiment contained 15 members provided by 15 different initial conditions from CTRL to remove the interference by atmospheric noise, and each member was integrated from May 1st to August 1st.

\section{Climatological features of the onset of the SASM}

\subsection{Definition and division of the SASM onset}

Monsoons are complex multi-scale phenomena, and defining their onsets has always been a controversial topic. Previous studies have tended to adopt the precipitation (Fasullo and Webster 2003; Pai and Rajeevan 2009; Wang and Ho 2002), wind (Taniguchi and Koike 2006; Wang et al. 2009; Webster and Yang 1992; Xing et al. 2015) and land-sea thermal contrast (represented by the meridional temperature gradient) (Mao et al. 2004; Xavier et al. 2007) to define the onset of the SASM. Generally, these definitions used to detect the onset of monsoon can be divided into two categories: (1) local-scale definitions and (2) regional to large-scale definitions (Bombardi et al. 2019). The definitions of monsoon onsets based on the land-sea thermal contrast and wind were designed to represent the heating gradient associated with the large-scale monsoon circulation and the continentalscale land-sea breeze, respectively. These large-scale definitions can accurately represent the monsoon interannual variability, but fail to capture the spatial patterns of the monsoon onset. Instead, definitions based on grid-cell scale precipitation (e.g., Wang and Ho 2002) can provide the onset date at the spatial resolution of the original dataset, which can also be aggregated in space to present large-scale phenomenon (Bombardi et al. 2019). Therefore, we adopt the definition of summer monsoon onset from Wang and Ho (2002): the first Julian pentad in which the relative pentad mean rainfall rate (relative to the January mean) exceeds $5 \mathrm{~mm} \mathrm{day}^{-1}$ is defined the summer monsoon onset.

The summer monsoon onset dates over the BOB $\left(10^{\circ}-20^{\circ}\right.$ $\left.\mathrm{N}, 85^{\circ}-95^{\circ} \mathrm{E}\right)$ and $\mathrm{AS}\left(8^{\circ}-20^{\circ} \mathrm{N}, 60^{\circ}-75^{\circ} \mathrm{E}\right)(\mathrm{Fig}$. 3a, green box) are obtained by using the spatial region mean relative pentad mean rainfall rates (Wang and Ho 2002), and the Indian summer monsoon onset is taken from the India Meteorological Department, which is defined by the onset of summer monsoon rainfall over the state of Kerala (Pai and Rajeevan 2009), circumventing uncertain effects caused by fewer grid points over the southern tip of the Indian Peninsula. 
(a) P24

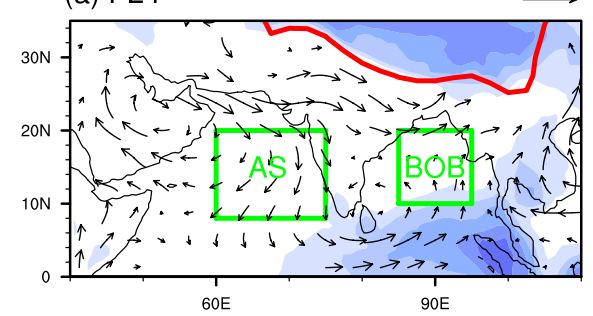

(d) P30

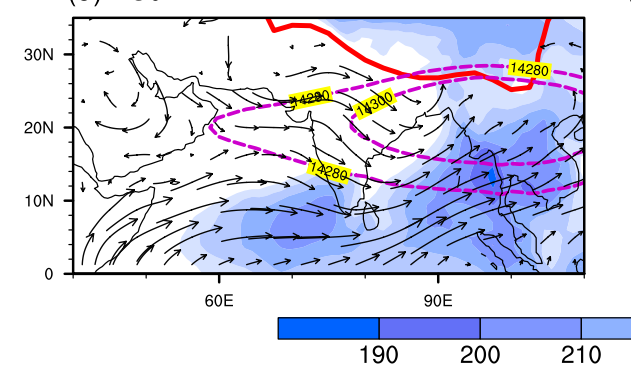

(b) P26

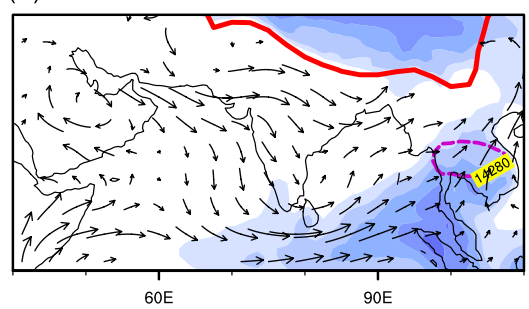

(e) P32

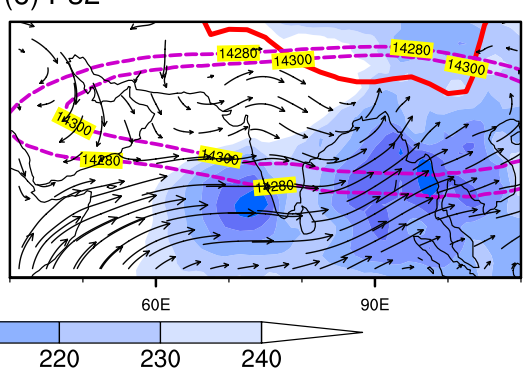

(c) P28

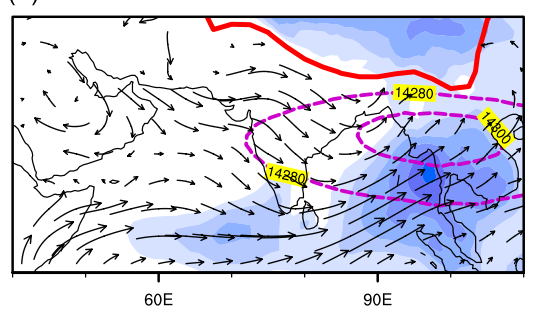

(f) Onset Date

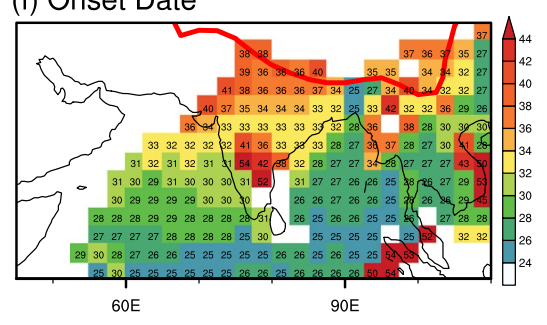

Fig. 3 Climate-mean OLR (shading, units: $\mathrm{W} \mathrm{m}^{-2}$ ) and 850-hPa wind (vectors, units: $\mathrm{m} \mathrm{s}^{-1}$ ) in the antecedent evolution of the SASM onset from pentad 24 to 32 (a-e). Magenta contours in a-e represent the 14,280 and 14,300 geopotential meters. The green boxes indicate

\subsection{Climatology of the SASM}

The SASM first begins over the eastern BOB in early May (Fig. $3 \mathrm{a}$ and $\mathrm{f}$ ), characterized by deep convection and a sudden transition of westerly at $850 \mathrm{hPa}$ (Fig. $3 \mathrm{a}$ and b) (Wu and Zhang 1998; Yu et al. 2015). With the gradually northward-moving deep convection, the summer monsoon over most regions in the BOB is fully established around mid-May (28th pentad), with the OLR below $230 \mathrm{~W} \mathrm{~m}^{-2}$ (Fig. 3c and f). Typically, OLR below $230 \mathrm{~W} \mathrm{~m}^{-2}$ indicates the outbreak of monsoon convection (Mao and Wu 2006; Mao et al. 2004; Tamura and Koike 2010; Wu and Zhang 1998). After that, the convection continues to advance eastwards rather than propagate westwards (Fig. 3f). Diabatic heating due to convection contributes to the warming of the central SAH (Qian et al. 2002), favoring a gradual development on the southern side of the SAH over the $\mathrm{BOB}$, enhancing the upper-level divergence-pumping (Liu et al. 2013) and further strengthening the convection. This configuration of the diabatic heating center and the SAH is conducive to the maintenance and development of the convection system. Then in late May, the strengthening and westward extension of the SAH and the intensive lowlevel westerly flow facilitate the summer monsoon onset over the AS and India (Fig. 3d and f). The summer monsoon onset over the AS occurs in pentads 28-30, while the onset of the Indian summer monsoon in the 31 st pentad. The summer monsoon onset over the northern Indian Peninsula is in late June, about 1 month later than that over the AS and BOB regions. $\mathbf{f}$ Pentad of monsoon onsets determined by the relative pentad-mean rainfall rate. The red contours indicate the $2000 \mathrm{~m}$ topographic height

the southern Indian Peninsula. These results are consistent with previous studies (Athira and Abhilash 2021).

It is noteworthy that the variability of the monsoon onset date over the three subregions of South Asia are closely related to each other (Fig. 4). The onset of the Indian summer monsoon closely follows the onset over the AS, with a correlation coefficient of 0.54 (statistically significant at the $99 \%$ confidence level), and the correlations between the onset over the BOB and that over both the AS and India are 0.28 (statistically significant at the

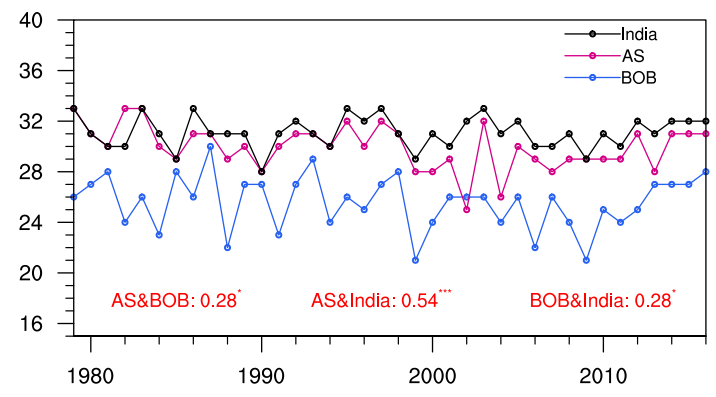

Fig. 4 Time series of summer monsoon onset dates (presented by the pentad of the year). The magenta, blue and black curves represent the summer monsoon onset over the AS, BOB, and India, respectively. The onset dates of the summer monsoon over the AS and BOB are based on the method of Wang and Ho (2002), while the Indian summer monsoon onset is from the Indian Meteorological Department. The correlation coefficients between them during the period 19792016 are marked at the bottom of each panel 
$90 \%$ confidence level). The early onset of the BOB summer monsoon accelerates the early increase in monsoon convection, causing considerable latent heat release, which may contribute to the precipitation over the AS and Indian Peninsula through modulating the development of the SAH to a certain degree (Liu et al. 2013; Xing et al. 2015).

The BOB summer monsoon onset is in early May, about one month earlier than that in the AS and India, the onset dates of which are in late May or early June. During the period between early May and early June, the diabatic heating over the TP increase rapidly owing to considerable precipitation condensation (Liu et al. 2020). Therefore, the huge thermal forcing of the TP in May cannot be ignored, raising the question as to whether it plays an important role in the onset of the SASM. We address this key issue in the next section.

\section{Influence of the thermal forcing over the TP on the SASM onset}

The anomalous heating in the seasonal transition may play an important role in determining the anomalous state of the Northern Hemisphere summer monsoon (Yasunari 1991). Simultaneously, with the increasing precipitation over the southeastern TP, the effect of the overall thermal forcing heating over the TP is quite considerable in May (Ye and Gao 1979).

\subsection{Connections between the thermal forcing of the TP and the onset date of the SASM}

Correlations between the AS, Indian and BOB summer monsoon onsets and the diabatic heating over the TP are shown in Fig. 5a-c. Obviously, the onset dates of the SASM, including that in the BOB, AS and India, are significant negatively related to the diabatic heating over the southern and southeastern TP and positively related to the diabatic heating over the northwestern TP. This seesaw pattern of correlation coefficients with a southeastern-northwestern inverse distribution over the TP is highly consistent with the leading EOF mode of the diabatic heating over the TP in May (Fig. 5d). Figure 5e shows the time series of the leading EOF mode (PC1), which is significantly related to the diabatic heating averaged over the TP $(r=0.58, p<0.01)$. To simplify the following analysis, the positive-southeastern-negativenorthwestern seesaw pattern of diabatic heating over the TP is called the positive seesaw pattern, and verse versa.

It is noteworthy that the seesaw pattern of diabatic heating over the TP in May has a significant negative correlation with the monsoon onset date in the AS, India and BOB, with the correlation relationships between them being $-0.70,-0.58$ and -0.35 (all statistically significant above the 95\% confidence level), respectively (Table 1). These relationships are more significant on interannual timescales, with all of them being statistically significant above the $95 \%$ confidence level, indicating that the increasing (decreasing) diabatic heating over the southeastern

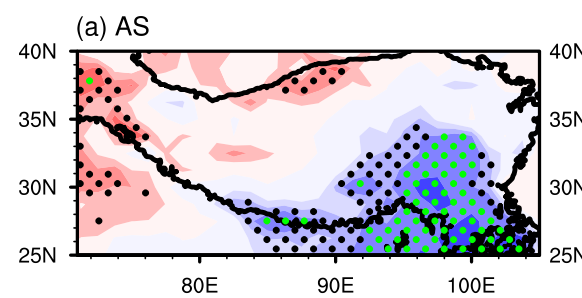

(d) EOF1

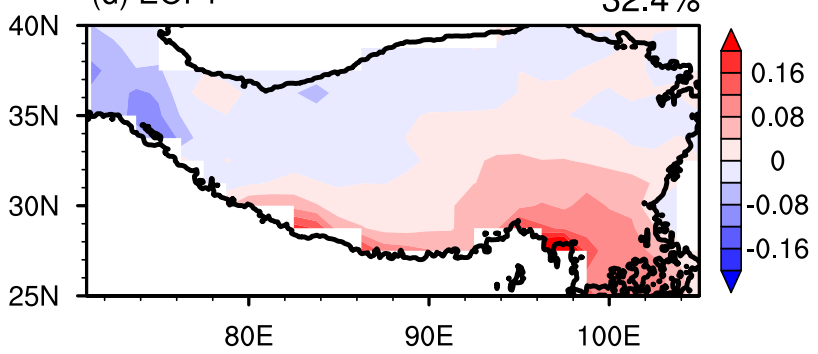

(b) India

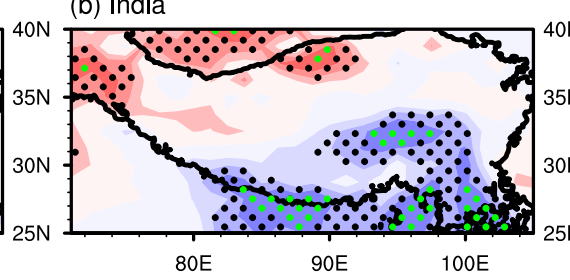

$100 \mathrm{E}$

(e)

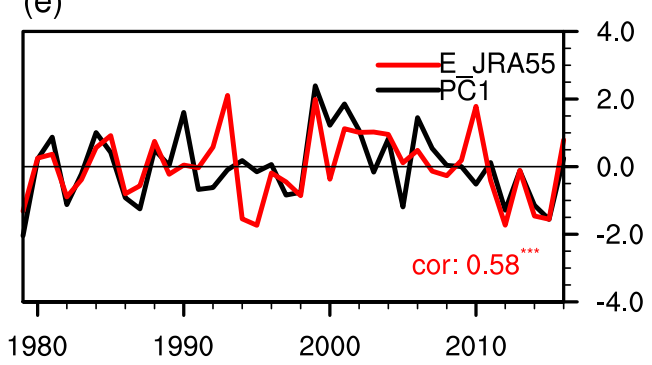

Fig. 5 Correlation pattern between the atmospheric heat source/sink (E) over the TP in May and summer monsoon onsets over a the AS, b India, and $\mathbf{c}$ the BOB. d First EOF mode of the atmospheric heat source/sink over the TP $(>2000 \mathrm{~m})$ in May during 1979-2016 based on JRA-55 datasets, and e the time series of PC1, and E_JRA55 that is the atmospheric heat source/sink over the TP estimated through
Eq. (3), with the correlation coefficient between them during the period 1979-2016 marked in e. The value in the upper right is the explained variance of the mode. Black and green dotted areas in a-c are where the statistical significance passed the $90 \%$ and $95 \%$ confidence levels, respectively. The black contours indicate the $2000 \mathrm{~m}$ topographic height 
Table 1 Correlation coefficients (first row) and partial correlation coefficients (last three rows) during 1979-2016 between PC1 and summer monsoon onset dates over the AS, India and BOB, having removed the influences from IPO (interdecadal Pacific Oscillation) index (second row), Niño3.4 index (thrid row) and SID (subtropical Indian Ocean dipole) index (fourth row) from December of the previous year to May of the current year. Statistical significance is shown by superscript asterisks: $* p<0.1, * * p<0.05$ and $* * * p<0.01$

\begin{tabular}{llll}
\hline & AS & India & BOB \\
\hline PC1 & $-0.70^{* * *}$ & $-0.58^{* * *}$ & $-0.35^{* *}$ \\
PC1(no IPO) & $-0.63^{* * *}$ & $-0.51^{* * *}$ & -0.22 \\
PC1(no Niño 3.4) & $-0.65^{* * *}$ & $-0.51^{* * *}$ & -0.22 \\
PC1(no SID) & $-0.69^{* * *}$ & $-0.54 * * *$ & $-0.31^{*}$ \\
\hline
\end{tabular}

Note that the IPO index is defined as the difference between the SST anomalies averaged over the central equatorial Pacific $\left(10^{\circ} \mathrm{S}-10^{\circ}\right.$ $\left.\mathrm{N}, 170^{\circ} \mathrm{E}-90^{\circ} \mathrm{W}\right)$ and that over the northwestern $\left(25^{\circ}-45^{\circ} \mathrm{N}, 140^{\circ}\right.$ $\left.\mathrm{E}-145^{\circ} \mathrm{W}\right)$ and southwestern $\left(50^{\circ}-15^{\circ} \mathrm{S}, 150^{\circ} \mathrm{E}-160^{\circ} \mathrm{W}\right)$ Pacific (Henley et al. 2015); the Niño 3.4 index $\left(5^{\circ} \mathrm{S}-5^{\circ} \mathrm{N}, 170^{\circ}-120^{\circ} \mathrm{W}\right.$; green boxes) is the area-averaged SST anomaly (Trenberth 1997); and the SID index is defined as the difference in SST anomalies between the western $\left(27^{\circ}-37^{\circ} \mathrm{S}, 55^{\circ}-65^{\circ} \mathrm{E}\right.$; red boxes $)$ and eastern $\left(18^{\circ}\right.$ $\mathrm{S}-28^{\circ} \mathrm{S}, 90^{\circ}-100^{\circ} \mathrm{E}$; red boxes) subtropical Indian Ocean (Behera and Yamagata 2001)

(northwestern) TP is conducive to the early (late) onset of the summer monsoon over the AS and India. Meanwhile, the close relationship between the diabatic heating over the TP and the BOB summer monsoon onset exists mainly over the southern slopes of the TP (Fig. 5c). As documented, the early onset of the BOB monsoon in early May contributes to a supply of abundant moisture to the southern TP during May, causing huge diabatic heating (Liu et al. 2019; Prasad 2005; Xing et al. 2015; Zhang et al. 2017).

SST anomalies and air-sea interactions are important factors that modulate the timing of the SASM (Deng et al. 2016; Liu et al. 2014b; Mao and Wu 2006; Wu and $\mathrm{Hu}$ 2015). Correlation coefficients between the onset of the Indian summer monsoon and the SST from the previous December to May in the current year shows that the most significant signals exhibit an interdecadal Pacific Oscillation (IPO)-like correlation pattern, an ENSO-related correlation pattern, and southern Indian Ocean dipole-related correlation pattern (Fig. S1). To explore whether the relationship between the seesaw pattern of diabatic heating over the TP (PC1) in May and the onset of the SASM is independent of the impacts from ocean signals, we adopted the partial correlation analysis shown in Table 1. Despite the influence from ocean signals having been controlled, the relationships between the diabatic heating over the TP and monsoon onset dates over the AS and India are still significant, passing the 99\% confidence levels (Table 1). Therefore, the seesaw pattern of diabatic heating over the TP in May can be considered as an independent precursor signal of the monsoon onset over the AS and India. Conversely, the correlation coefficients between the monsoon onset dates over the AS and India and the ocean signals (including the IPO, ENSO and subtropical Indian Ocean dipole in May) dramatically decrease after controlling the influence of the seesaw pattern of diabatic heating over the TP (Table S1). These partial correlation analysis results indicate that, although the preceding IPO, ENSO and subtropical Indian Ocean dipole can influence the monsoon onset over the AS and India (Fig. S1 and Table S1), the effect of the diabatic heating over the TP in May is more dominant.

The onset of the BOB monsoon in early May contributes to the positive seesaw pattern of diabatic heating over the $\mathrm{TP}$, especially the atmospheric heating over the southern slopes of the TP (Fig. 5c), but this impact of the onset of the $\mathrm{BOB}$ monsoon is no longer robust after removing the influence of ENSO and the IPO (Table 1). The above results confirm the statistical relationships between the seesaw pattern of diabatic heating over the TP in May and the SASM onset over the AS and India, so the physical mechanism underlying these relationships is worthy of exploration.

\subsection{Impacts of the thermal forcing of the TP on the onset of the SASM}

Composite and regression analysis are employed to exhibit the atmospheric circulation associated with the seesaw pattern of the diabatic heating over the TP in May. Nine years of positive seesaw patterns of diabatic heating over TP (i.e., 1981, 1984, 1990, 1999, 2000, 2001, 2002, 2004 and 2006) and ten years of negative seesaw patterns (i.e., 1979, 1982, 1986, 1987, 1997, 1998, 2005, 2012, 2014 and 2015) were selected for the composite analysis. The criterion was \pm 0.75 standard deviations for the PC1 time series during 1979-2016 (black curve in Fig. 5e). Note that the results were unaffected by the choice of threshold (Fig. S2).

Figure 6 shows the regression of circulation including wind, moisture transport, temperature at the mid-upper troposphere, and OLR in May against PC1 of the TP diabatic heating. The positive seesaw pattern of diabatic heating over the TP in May induces strong upward motion over the southern TP and downward motion over the western TP and even over the Iranian Plateau (Fig. 6b)-results that are consistent with previous studies (Liu et al. 2017; Wu et al. 2012). The downward motion over the western TP and Iranian Plateau together with moisture divergence, suppresses the local precipitation and convection (Fig. 6c, $\mathrm{d}$ and $\mathrm{f}$ ), increases the temperature over the western TP in the mid-upper troposphere (500-200 hPa) (Figs. 6e and $7 \mathrm{a})$. The thermal structure in the upper troposphere can reflect the land-sea thermal gradient better than in the lower troposphere (Dai et al. 2013) and dominate the summer monsoon onset (Zhou et al. 2020). Thus, the warming temperature in the mid-upper troposphere over the western 

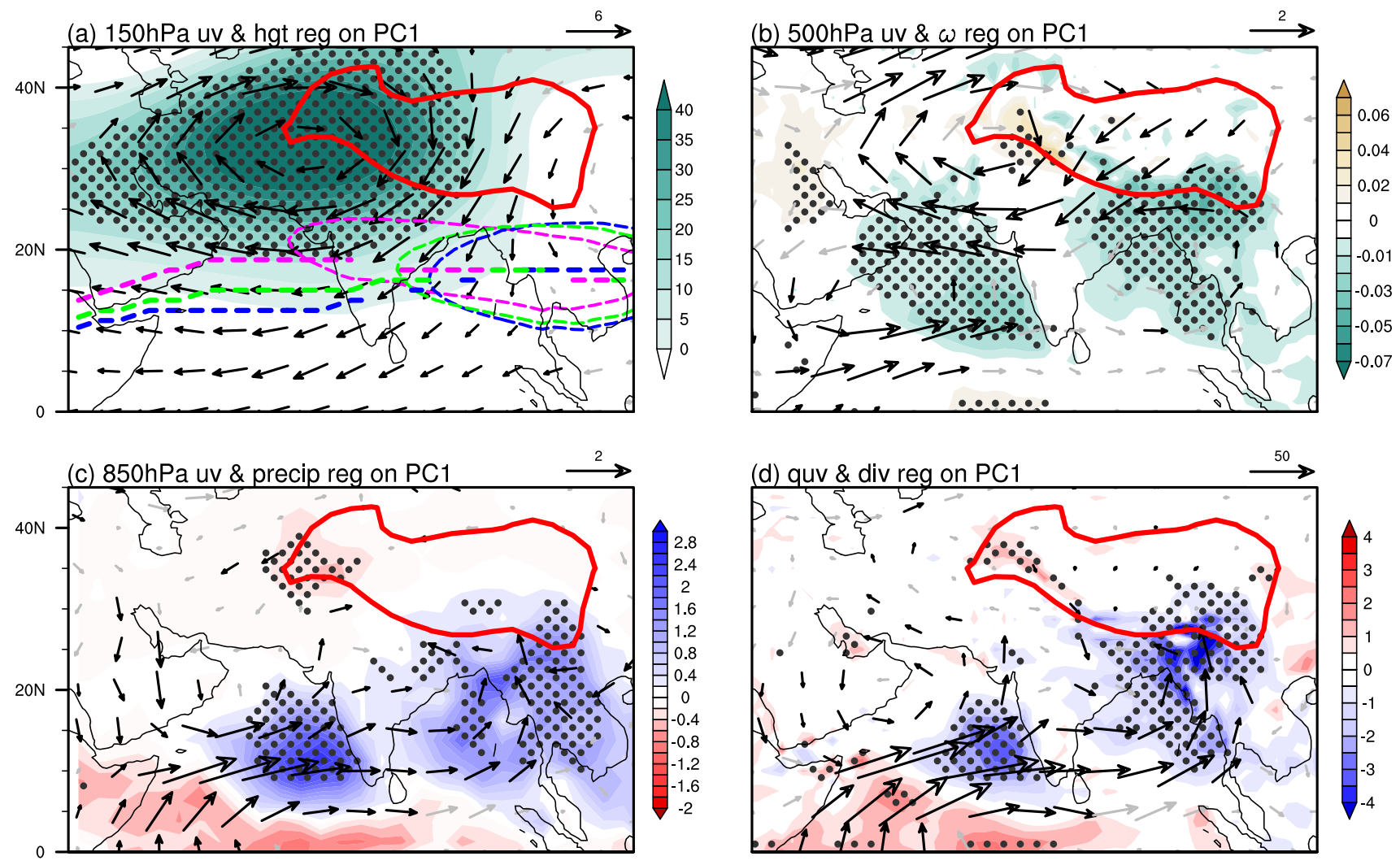

(e) $500-200 \mathrm{hPa}$ T reg on PC1

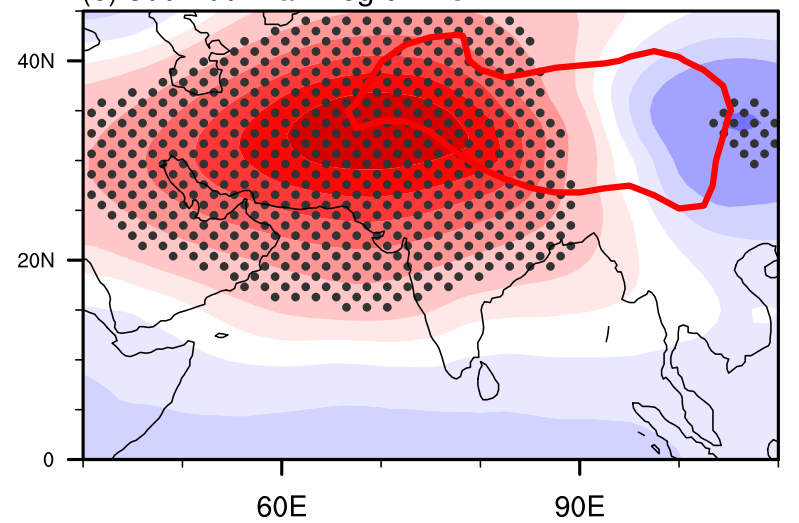

Fig. 6 Regression of atmospheric variables in May quantities against the PC1 of the atmospheric heat source over the TP in May during 1979-2016: a 150-hPa geopotential height (shading, unit: gpm) and $150-\mathrm{hPa}$ wind (vectors, units: $\mathrm{m} \mathrm{s}^{-1}$ ); b $500-\mathrm{hPa}$ vertical velocity (shading, units: $\mathrm{Pa} \mathrm{s}^{-1}$ ) and 500-hPa wind (vectors, units: $\mathrm{m} \mathrm{s}^{-1}$ ); $\mathbf{c}$ precipitation (shading, units: $\mathrm{mm} \mathrm{day}{ }^{-1}$ ) and $850-\mathrm{hPa}$ wind (vectors, units: $\mathrm{m} \mathrm{s}^{-1}$ ); $\mathbf{d}$ surface to $100-\mathrm{hPa}$ vertically integrated moisture divergence (shading, units: $10^{-5} \mathrm{~kg} \mathrm{~m}^{-2} \mathrm{~s}^{-1}$ ) and moisture trans-

TP facilitates the early transition of the meridional temperature gradient (Mao et al. 2004), and further supports the early onset of summer monsoon rainfall over the AS and India (Fig. 6c, d). Meanwhile, because the center of the SAH tends to move towards the area with the larger heating rate (Cen et al. 2020; Qian et al. 2002), the

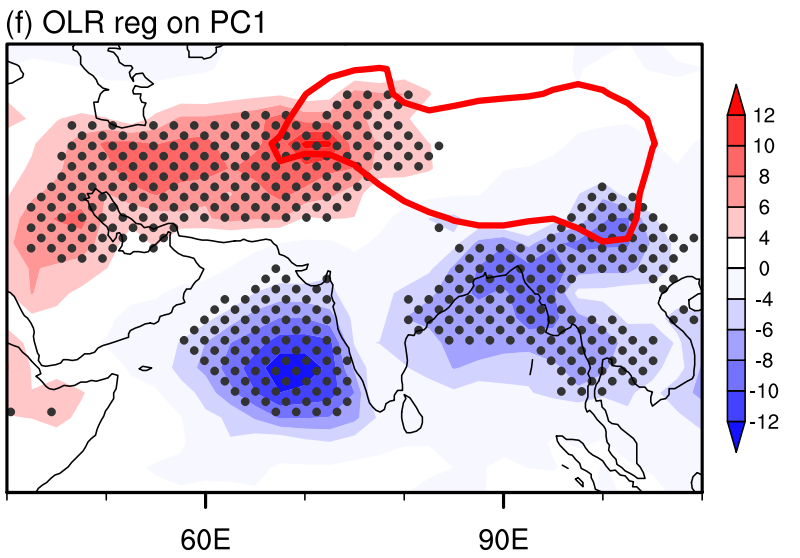

port anomalies (vectors, units: $\mathrm{kg} \mathrm{m}^{-1} \mathrm{~s}^{-1}$ ); e temperature vertically averaged over 500-200 hPa (shading, unit: K); and f OLR (shading, units: $\mathrm{W} \mathrm{m}^{-2}$ ). The green, magenta and blue contours (curves) in a indicate the composite 14,280 geopotential heights (the ridgelines of the $\mathrm{SAH}$ ) in the climatology, in positive $\mathrm{PC} 1$ years and negative $\mathrm{PC} 1$ years. Black dotted areas and black vectors indicate statistical significance at or above the $99 \%$ confidence level. The red contours indicate the $2000 \mathrm{~m}$ topographic height

strengthened SAH is located to the west of its climatemean position, with its ridgeline located at near $20^{\circ} \mathrm{N}$ (Fig. 6a) (Liu et al. 2020; Yu et al. 2020). $u \approx 0, \frac{\partial u}{\partial y}>0$ is defined as the ridgeline of the SAH (Liu et al. 2014a). The easterly along with the southern flank of the SAH 
(a) $\partial T$ $\frac{\partial T}{\partial t}$

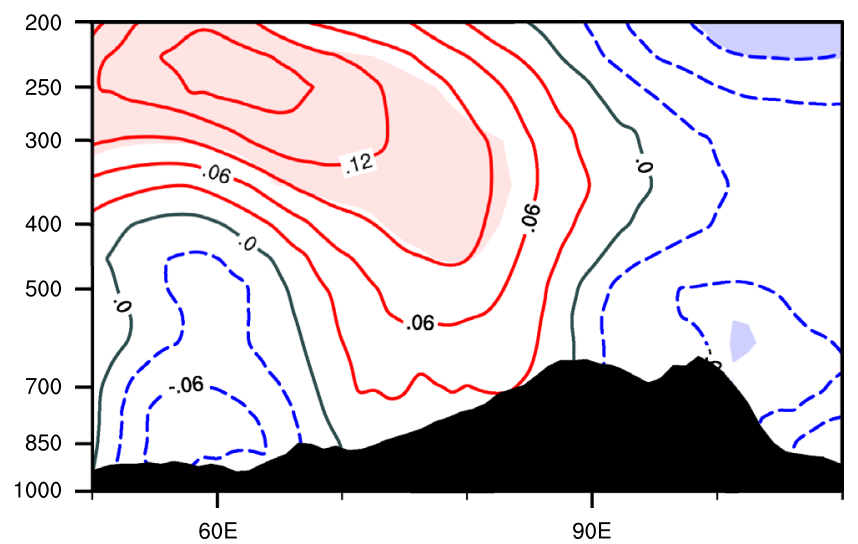

(c) $-\omega\left(\frac{\partial T}{\partial p}-\frac{\alpha}{C_{p}}\right)$

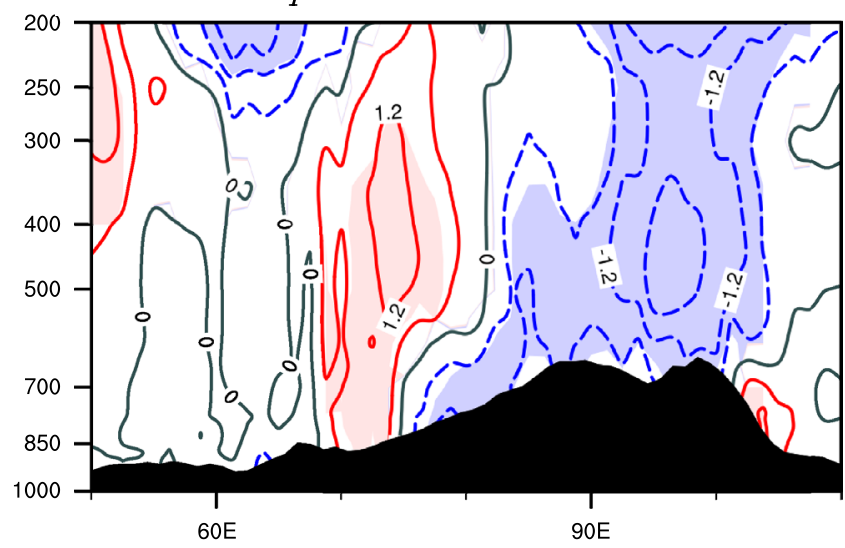

Fig. 7 Composite differences in the meridionally averaged $\left(25^{\circ}-40^{\circ}\right.$ N) temperature budget between the positive and negative seesaw pattern of diabatic heating over the TP: a temperature tendency $(\partial T / \partial t)$; b horizontal advection of temperature $(-\operatorname{adv} . T)$; c adiabatic heating $\left(\omega\right.$ term); and $\mathbf{d}$ diabatic heating $\left(\boldsymbol{Q}_{1} / \boldsymbol{c}_{\boldsymbol{p}}\right.$ (contours, units: $\mathrm{K}$ day $\left.{ }^{-1}\right)$

superimposes well with the low-level westerly and moisture convergence, which supports the early onset of the monsoon rainfall over the AS and India (Fig. 6c, d).

The temperature budget equation can elucidate the physical mechanisms contributing to the warming air column over the western TP. The temperature tendency $(\partial T / \partial t)$ at each pressure level can be estimated using the following equation:

$\frac{\partial \mathbf{T}}{\partial \mathbf{t}}=-\left(\mathbf{u} \frac{\partial \mathbf{T}}{\partial \mathbf{x}}+\mathbf{v} \frac{\partial \mathbf{T}}{\partial \mathbf{y}}\right)-\omega\left(\frac{\partial \mathbf{T}}{\partial \mathbf{p}}-\frac{\boldsymbol{\alpha}}{\mathbf{c}_{\mathbf{p}}}\right)+\frac{\mathbf{Q}_{1}}{\mathbf{c}_{\mathbf{p}}}$,

where $T$ is the air temperature; $t$ is time; $u, v$ and $\omega$ represent the zonal, meridional and vertical velocity, respectively; $p$ is pressure, $\boldsymbol{c}_{\boldsymbol{p}}$ is the specific heat at constant pressure, $\boldsymbol{\alpha}$ represents the specific volume; and $\boldsymbol{Q}_{1}$ is the atmospheric apparent heat source (Yanai et al. 1973). The temperature (b) -adv.T

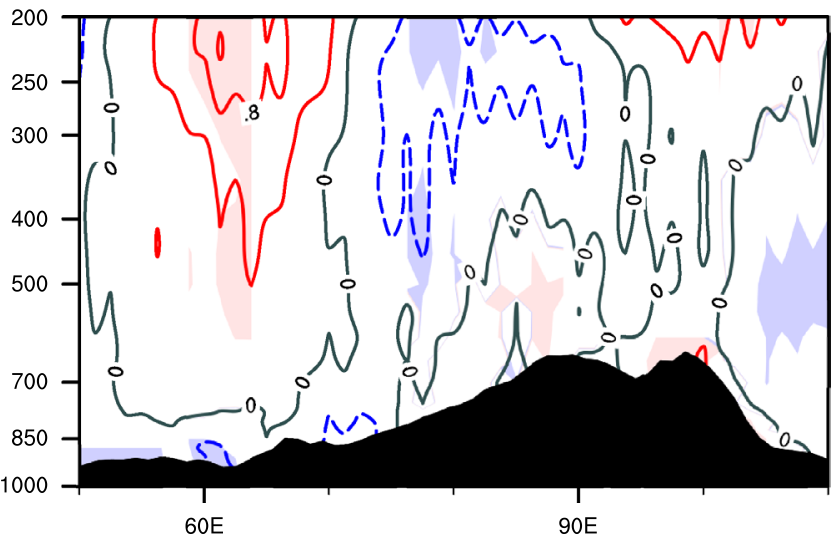

(d) $\frac{Q 1}{C_{p}}$

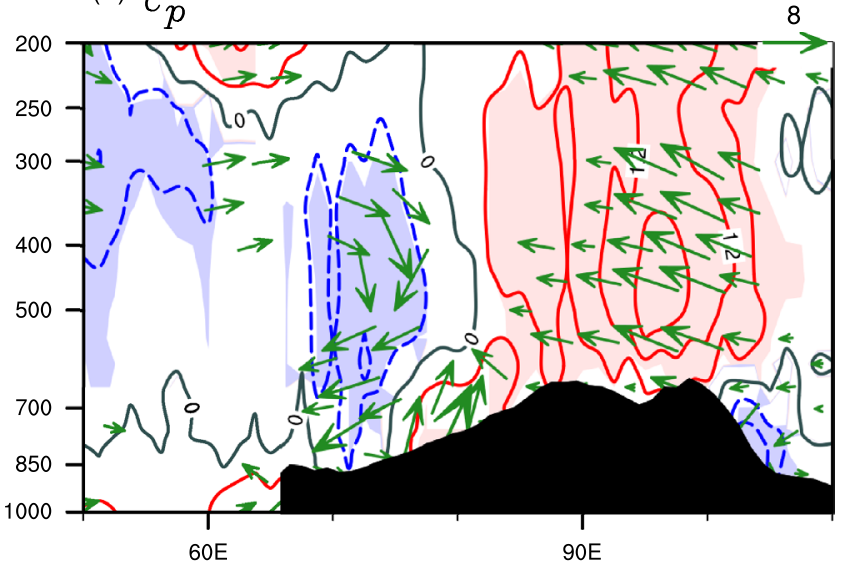

and zonal circulation (vectors, units: $v$ in $\mathrm{m} \mathrm{s}^{-1},-3 \omega$ in $10^{-2} \mathrm{~Pa} \mathrm{~s}^{-1}$ ). The red, blue shading and green vectors indicate statistical significance at or above the $95 \%$ confidence level. The black shading indicates the topography

tendency $(\partial \boldsymbol{T} / \partial \boldsymbol{t})$ consists of the horizontal advection of temperature term $\left(-\left(\boldsymbol{u} \frac{\partial \boldsymbol{T}}{\partial \boldsymbol{x}}+\boldsymbol{v} \frac{\partial \boldsymbol{T}}{\partial y}\right)\right)$, adiabatic heating term $\left(-\omega\left(\frac{\partial T}{\partial \boldsymbol{p}}-\frac{\alpha}{c_{p}}\right)\right)$, and diabatic heating term $\left(\boldsymbol{Q}_{1} / \boldsymbol{c}_{\boldsymbol{p}}\right)$. In fact, the $\boldsymbol{Q}_{1}$ is computed via the temperature budget equation, and the correlation coefficient between $\boldsymbol{Q}_{1}$ and $\boldsymbol{E}_{\text {JRA55 }}$ is 0.93, further verifying the consistency of the TP diabatic heating between the reverse and direct computational methods.

The diagnosis with the temperature budget equation (Fig. 7) shows that the warming air column over the western TP is significantly linked with the seesaw pattern of diabatic heating over the TP. The strong upward motion over the eastern TP and downward motion over the western TP (Fig. 7d) is also detected in Fig. 6b. Over the eastern TP, strong diabatic heating causes significant upward motion, and the increasing temperature due to diabatic heating to the 
east of $90^{\circ} \mathrm{E}$ is offset by the decreasing adiabatic heating due to upward motion, leading to cooling over the eastern TP. Between $80^{\circ} \mathrm{E}$ and $90^{\circ} \mathrm{E}$, meanwhile, the diabatic heating dominantly contributes to the warming air column (Fig. 7a, d). Over the western TP, the warming air column is mainly attributed to the strong adiabatic heating due to the downward motion (Fig. 7c) and the subsequent horizontal advection of temperature caused by the conservation of mass in the mid-upper troposphere (Fig. 7b).

To further illustrate the influence of the seesaw pattern of diabatic heating over the TP on the summer monsoon onset dates of the AS and India, the temporal evolutions of the composite OLR, SAH and temperature in the mid-upper troposphere between positive and negative seesaw pattern years are shown in Fig. 8. The climate-mean monsoon convection (low OLR) firstly starts at around $90^{\circ} \mathrm{E}$ during the beginning of May, signifying the summer monsoon onset over the BOB, and the monsoon over the AS and India break out around the end of May along with the westward-extending SAH represented by the 14,280-gpm isoline (Fig. 8a, b). When the temperature ridge reaches to $20^{\circ} \mathrm{N}$ at around 1 June (Fig. 8c, d), this means the meridional temperature gradient within the latitudinal band of $10^{\circ}-20^{\circ} \mathrm{N}$ is positive and signals the onset of the SASM (Mao et al. 2002). In the years of positive seesaw patterns of diabatic heating over the TP, the temperature ridge reaches to $20^{\circ} \mathrm{N}$ earlier, in mid-May, with strong monsoon convection and a westward-extending SAH appearing around the AS (India) in

\section{OLR}

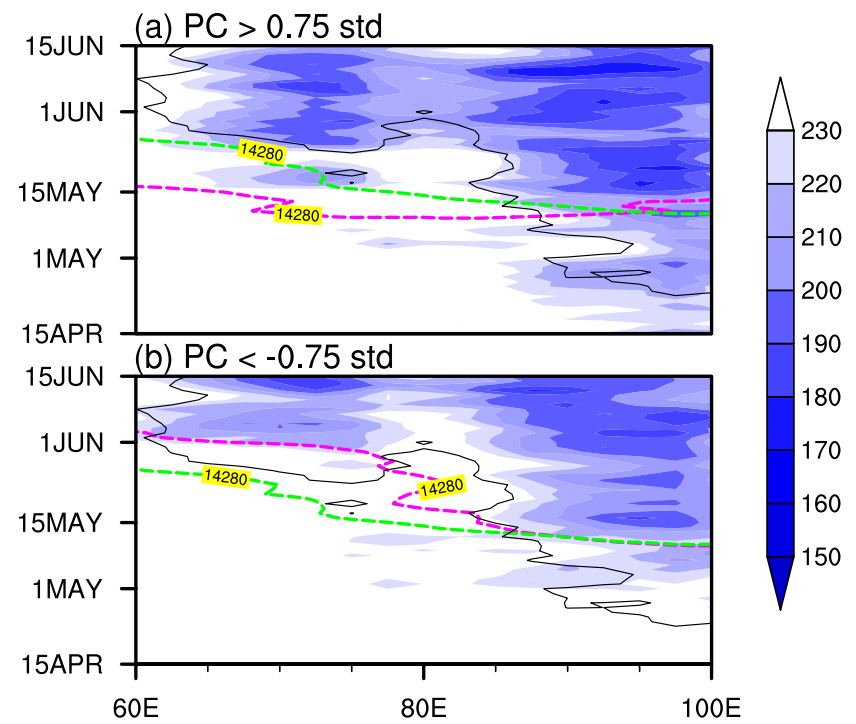

Fig. 8 Composite evolution of $\mathbf{a}, \mathbf{b}$ meridionally averaged $\left(5^{\circ}-15^{\circ} \mathrm{N}\right)$ OLR (shading, units: $\left.\mathrm{W} \mathrm{m}^{-2}\right)$ and $\mathbf{c}, \mathbf{d}$ zonally averaged $\left(50^{\circ}-90^{\circ} \mathrm{E}\right)$ temperature, vertically averaged over 500-200 hPa (shading, unit: K) for $\mathbf{a}, \mathbf{c}$ PC $>0.75$ standard deviation years, $\mathbf{b}, \mathbf{d}$ PC $<-0.75$ standard deviation years. The black contour represents $230 \mathrm{~W} \mathrm{~m}^{-2}(\mathbf{a}, \mathbf{b})$ and
mid-May (late-May) (Fig. 8a). During the years with a negative seesaw pattern, meanwhile, the SASM onset is delayed to early June (Fig. 8d). The strong monsoon convection and westward-extending SAH over the AS and India are significant after early June (Fig. 8b).

The above results indicate that the diabatic heating over the TP plays an important role in the early/late onset of the SASM. On the one hand, the seesaw pattern of diabatic heating induces the anomalous warming in the mid-upper troposphere over the western TP, providing a favorable meridional temperature transition for the occurrence of the monsoon rainfall over the AS and India. On the other hand, the westward movement of the SAH associated with the diabatic heating over the TP leads to upper-level divergence-pumping over the AS and India, which superimposes over the lowlevel westerly and supports favorable vertical circulation over the two regions (Liu et al. 2013, 2014b).

\section{Simulation of the impacts of the thermal forcing over the TP on the onset of the SASM}

The data diagnosis shows that the seesaw pattern of diabatic heating over the TP is beneficial to the SASM onset, including the summer monsoon over the AS and India. Examining the onset of the SASM represented by the mid-upper tropospheric temperature in the sensitivity runs (Fig. 9) reveals

\section{Temp $(500-200 \mathrm{hPa})$}

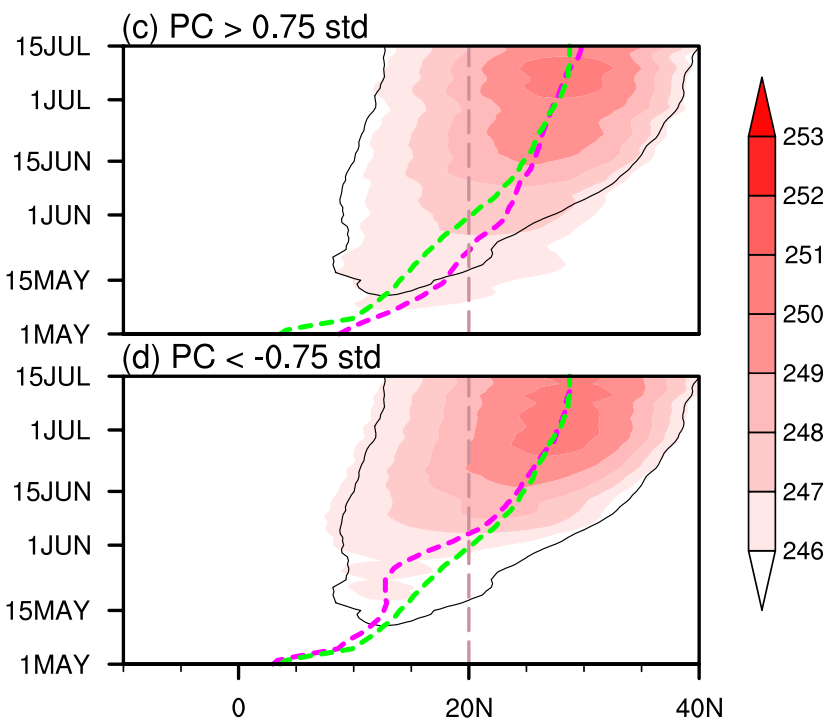

$246 \mathrm{~K}(\mathbf{c}, \mathbf{d})$ for climatological mean. The green (magenta) curves in a, $\mathbf{b}$ and $\mathbf{c}, \mathbf{d}$ indicate the 14,280 geopotential height at $20^{\circ} \mathrm{N}$ and the maximum ridge line, respectively, for climate mean states ( $\mathrm{PCl}>0.75$ standard deviation years). The light pink denotes $20^{\circ} \mathrm{N}$ 
that the mid-upper temperature ridge that responds to the strong (weak) diabatic heating over the eastern TP in May reaches $20^{\circ} \mathrm{N}$ earlier (later) than the climate-mean state, i.e., the SASM onset is around mid-May when strong diabatic heating over the eastern TP is set in EXP_POS, while it is delayed to around early June in EXP_NEG (Fig. 9). Hence, the response of the SASM onset represented by the meridional temperature gradient under strong or weak diabatic heating over the eastern TP in May is indeed advanced or delayed.

Figure 10 shows the difference in circulation and precipitation in May between EXN_POS and EXN_NEG to detect the physical effect of the thermal forcing of the TP in May. As mentioned in Sect. 4.2, the circulation response to the diabatic heating over the eastern TP in May supports an early onset of the SASM, including the summer monsoon over the AS and India. In the upper troposphere, the diabatic heating over the TP leads to the westward movement of the SAH, enhancing upper-level divergence-pumping over the AS and India (Fig. 10a, b). The easterly, along with the southern flank of the SAH, coordinates well with the lower-level southwesterly, and forms a summer circulation structure favorable to precipitation in the SASM regions (Fig. 10a, c). In the lower troposphere, the westerly and abundant moisture transport over the AS and India result in significant above-normal precipitation over the eastern AS and western coast of the Indian Peninsula. In addition,

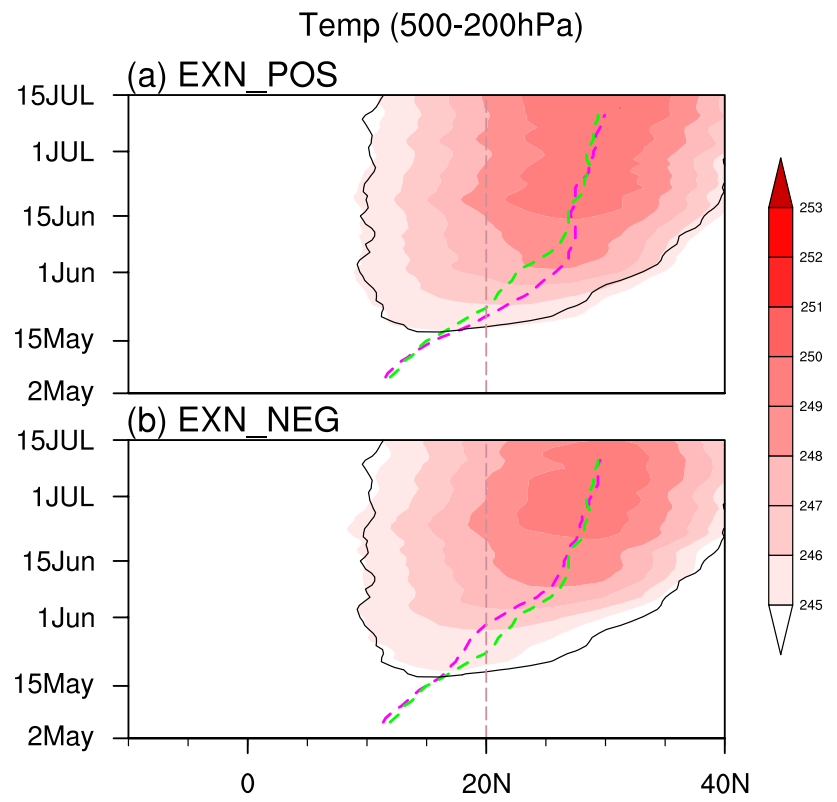

Fig. 9 Zonally averaged $\left(50^{\circ}-90^{\circ} \mathrm{E}\right)$ temperature, vertically averaged over 500-200 hPa (shading, unit: K) for a EXP_POS, b EXP_NEG. The black contour represents $246 \mathrm{~K}$ for climatological mean. The magenta and green curves indicate the maximum ridge line for sensitive experiment (EXP_POS and EXP_NEG) and control experiment (CTRL). The light pink line denotes $20^{\circ} \mathrm{N}$ significant upward motion appears over the southeastern $\mathrm{TP}$, accompanied by downward motion over its surrounding regions, especially the western TP and Iranian Plateau, in the difference between EXN_POS and EXN_NEG (Fig. 10b), and the response of these vertical movements over the eastern and western TP is intensified with the expansion of the diabatic heating over the eastern TP (Fig. 11a-e). This adiabatic heating caused by the anomalous vertical motions over the TP, and the warm advection of temperature by the easterly anomaly in the mid-upper troposphere, gradually heats the mid-upper troposphere (Fig. 11f-i). As a result, the increasing mid-upper temperature over the TP regions enhances the land-sea thermal contrast and contributes to an early transition of the meridional temperature gradient (Fig. 9a), further supporting the advanced summer monsoon onset. All these results are generally consistent with the data analysis reported in Sect. 4.2.

However, inevitably, there are some differences between the results of the numerical experiments and the data analysis, which may be related to the lack of atmosphere-ocean interaction in the AGCM and the intensity of the heating source set over the eastern TP. For instance, the rain belts and westerly over the AS and India shift northwards significantly. The anticyclone (Fig. 10a) and increasing mid-upper tropospheric temperature (Fig. 11) in the difference between EXN_POS and EXN_NEG are more significant over the eastern TP. There are significant downward motions and negative precipitation over the northern Indian Peninsula and Indo-China Peninsula associated with strong upward motion and positive precipitation over the eastern TP. The possible reasons for these differences are as follows, i.e., the positive heat source set in the sensitivity runs may trigger a weaker response of the circulation in other regions; while in contrast, the response of the circulation over the eastern TP seems more significant. Nevertheless, the simulated general circulation features associated with anomalous thermal forcing over TP in May agree with the data analysis, which further confirms the significant effect of the thermal forcing over the TP on the early/late onset of the SASM, including the summer monsoon over the AS and India.

\section{Summary and discussion}

\subsection{Summary}

Using station datasets from 80 meteorological stations over the TP, JRA-55 data, and OLR and SST from NOAA during 1979-2016, the connections between the thermal forcing of the TP and summer monsoon onset over South Asia, including the AS, India, and BOB, were investigated. Moreover, sensitivity experiments based on CAM4.0 were used to 
(a) $150 \mathrm{hPa}$ uv \& hgt

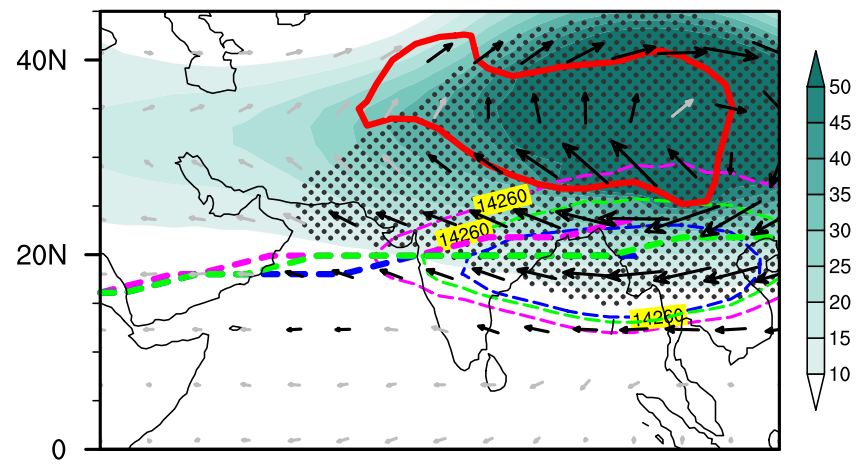

(c) $850 \mathrm{hPa}$ uv \& precip

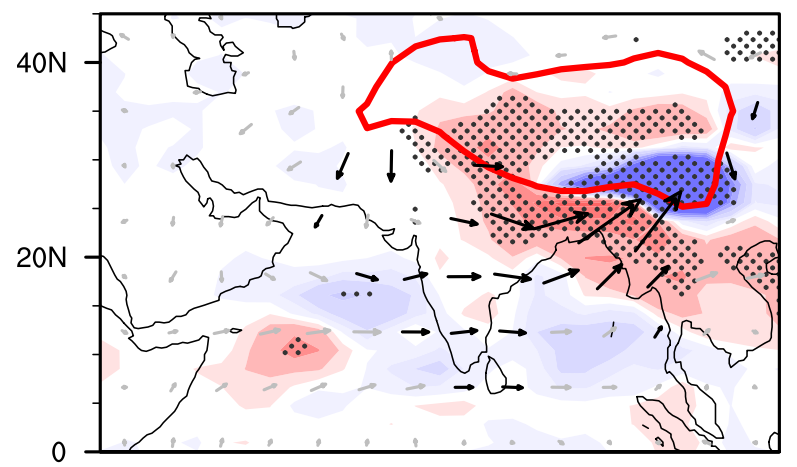

(e) $500-200 \mathrm{hPa} \mathrm{T}$

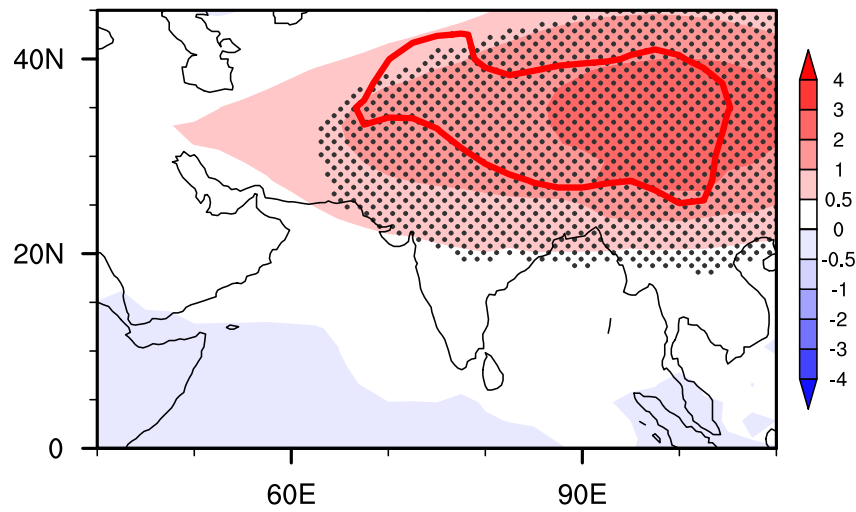

Fig. 10 Differences in May quantities between EXP_POS and EXP_NEG: a 150-hPa geopotential height (shading, unit: gpm) and $150-\mathrm{hPa}$ wind (vectors, units: $\mathrm{m} \mathrm{s}^{-1}$ ); b $500-\mathrm{hPa}$ vertical velocity (shading; units: $\mathrm{Pa} \mathrm{s}^{-1}$ ) and 500-hPa wind (vectors, units: $\mathrm{m} \mathrm{s}^{-1}$ ); precipitation (shading, units: $\mathrm{mm} \mathrm{day}^{-1}$ ) and $850-\mathrm{hPa}$ wind (vectors; units: $\mathrm{m} \mathrm{s}^{-1}$ ); d surface to $100-\mathrm{hPa}$ vertically integrated moisture divergence (shading, units: $10^{-5} \mathrm{~kg} \mathrm{~m}^{-2} \mathrm{~s}^{-1}$ ) and moisture transport

further confirm the physical mechanisms involved. The main conclusions can be summarized as follows:

(1) The leading mode of the diabatic heating over the TP in May, established through EOF analysis, shows a seesaw pattern with a southeastern-northwestern dipole distri-
(b) $500 \mathrm{hPa}$ uv $\& \omega$

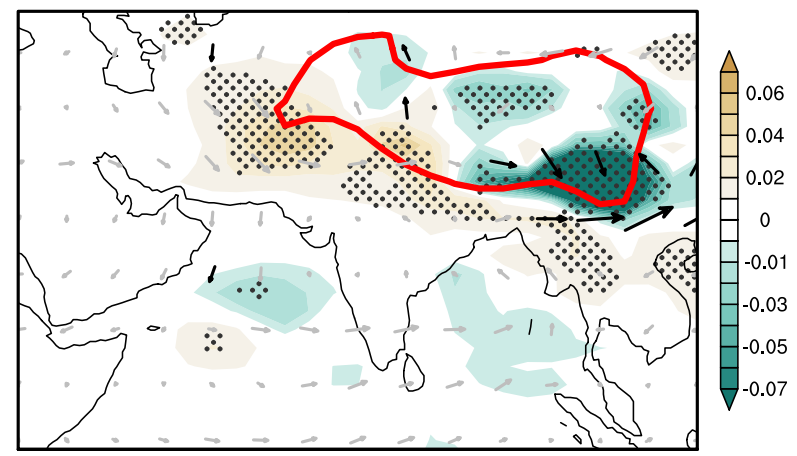

(d) quv \& div $\stackrel{90}{\longrightarrow}$

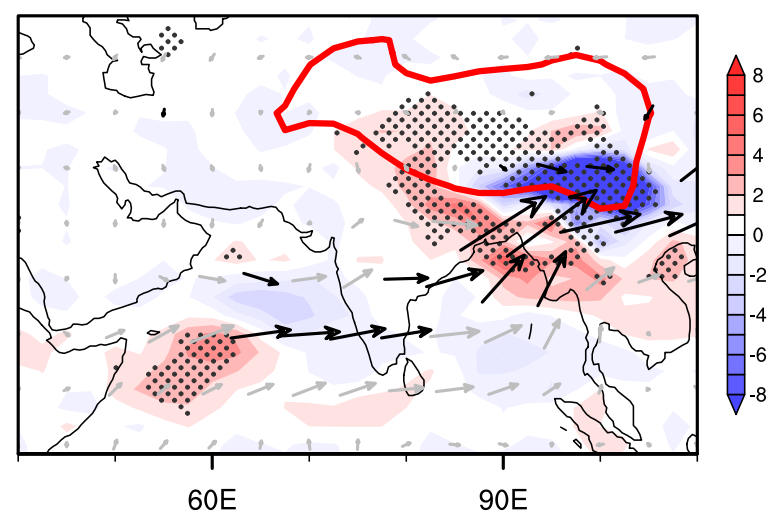

anomalies (vectors, units: $\mathrm{kg} \mathrm{m}^{-1} \mathrm{~s}^{-1}$ ); e temperature, vertically averaged over $500-200 \mathrm{hPa}$ (shading, unit: $\mathrm{K}$ ). The green, magenta and blue contours (curves) in a indicate the composite 14,260 geopotential heights (the ridgelines of the SAH) in CTRL, EXP_POS and EXP_NEG, respectively. Black dotted areas and black vectors indicate statistical significance at or above the $90 \%$ confidence levels. The red contours indicate the $2000 \mathrm{~m}$ topographic height

bution. A positive diabatic heating pattern is linked to an early onset of the summer monsoon over the AS and India. This relationship is independent of ENSO, IPO, and the southern Indian Ocean dipole. The anomalous seesaw pattern of diabatic heating over the TP in May, therefore, can be considered as an independent precur- 

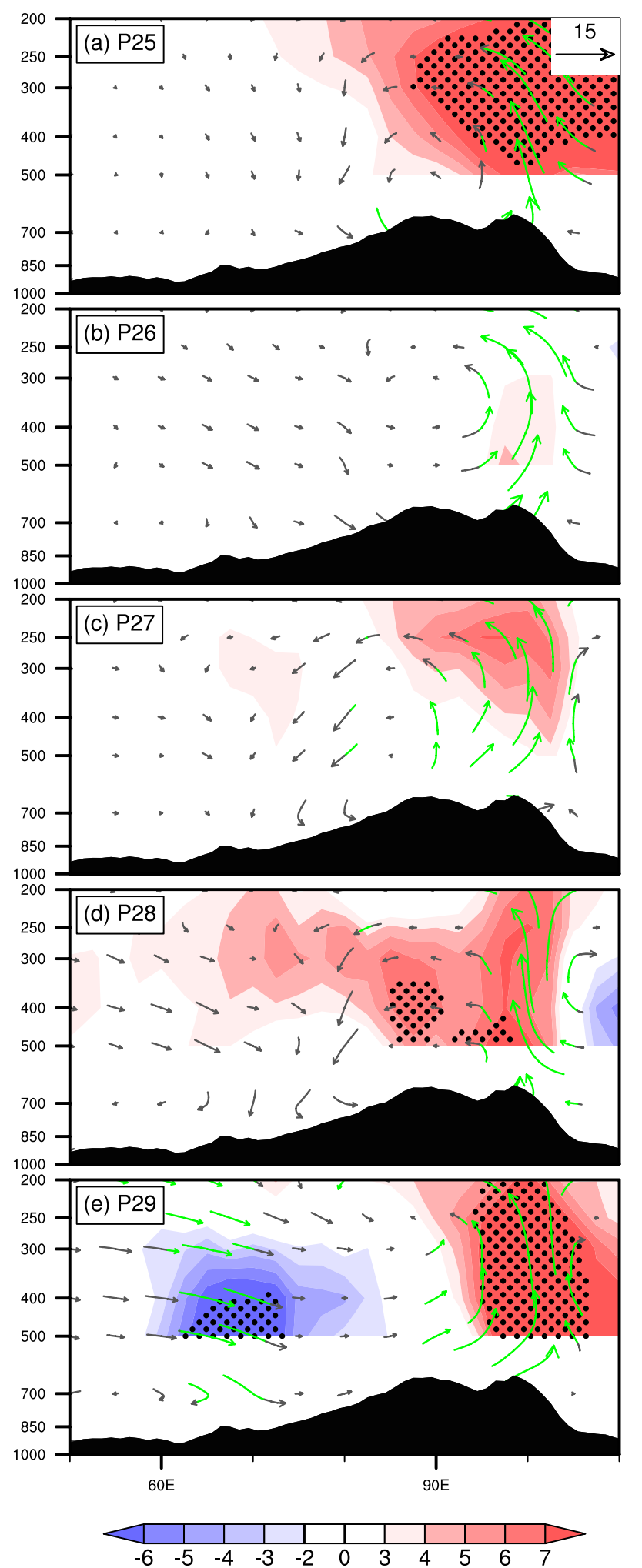

Fig. 11 Differences in a-e meridionally averaged $\left(25^{\circ}-40^{\circ} \mathrm{N}\right)$ diabatic heating (contours, units: $\mathrm{W} \mathrm{m}^{-2}$ ) and zonal circulation (vectors, units: $\boldsymbol{v}$ in $\mathrm{m} \mathrm{s}^{-1},-3 \boldsymbol{\omega}$ in $10^{-2} \mathrm{~Pa} \mathrm{~s}^{-1}$ ) and $\mathbf{f}-\mathbf{i}$ air temperature (con-
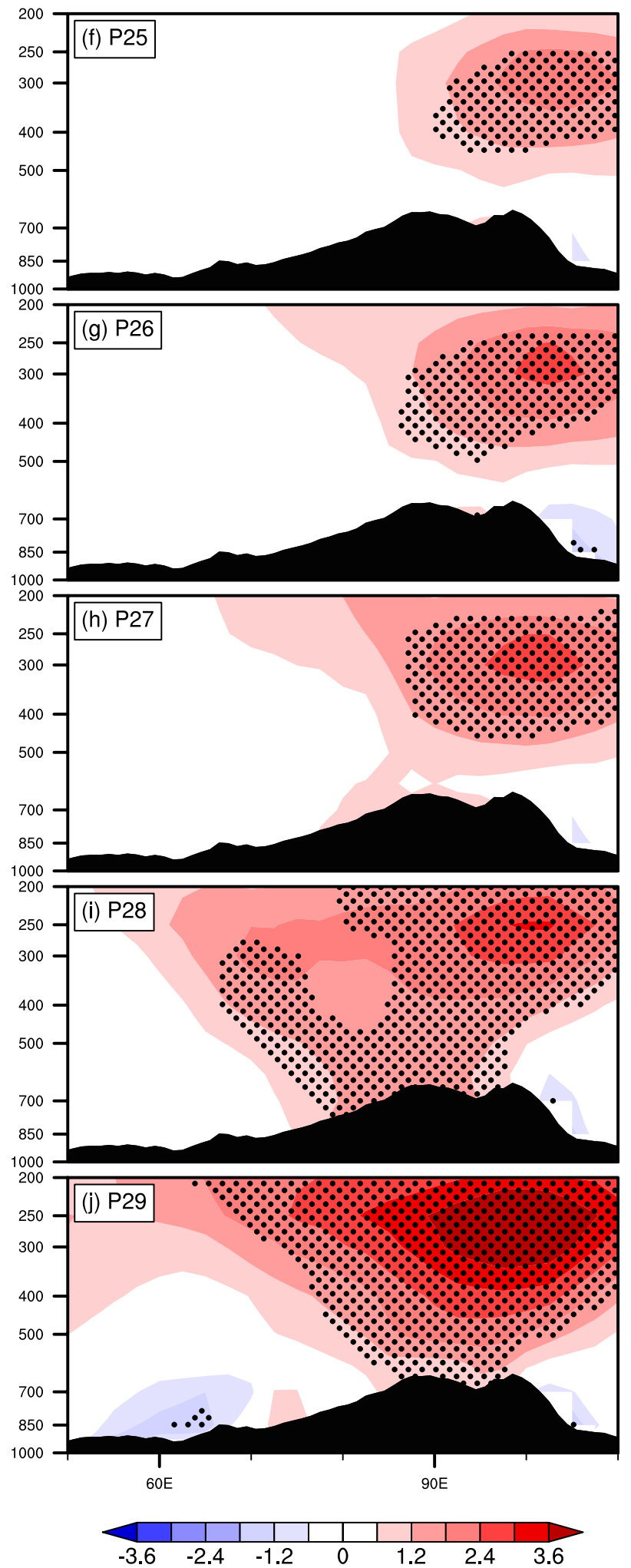

tours, unit: K) between EXP_POS and EXP_NEG from the 25th to 29 th pentad. Black dotted areas and green vectors indicate statistical significance at or above the $90 \%$ confidence level 
sor signal for the onset of monsoon over the AS and India. Meanwhile, the relationship between the diabatic heating over the TP and the onset of the BOB summer monsoon mainly appears over the southern slopes of the TP.

(2) The seesaw pattern of the diabatic heating anomaly over the TP in May can trigger an anomalous response of vertical motion over the TP. The diabatic heating over the eastern TP, adiabatic heating due to downward motion over the western TP, and warm horizontal advection heating stimulated by the anomalous vertical motion, induce the warming in the mid-upper troposphere over the western TP, providing a favorable meridional temperature transition for the occurrence of monsoon rainfall over the AS and India, thus supporting an early monsoon onset. Furthermore, the westward movement of the SAH associated with the seesaw pattern of diabatic heating over the TP strengthens the upper-level divergence-pumping over the AS and India, and the easterly-along with the southern flank of the SAH-superimpose well with the low-level westerly flow, further stimulating the onset of the SASM, including the summer monsoon over the AS and India.

(3) Numerical experiments based on the atmospheric component of CAM4.0 further confirm that the positive seesaw pattern of diabatic heating over the TP in May facilitates a westward-extended SAH, intensifying the anticyclone over the TP, warming the temperature in the mid-upper troposphere, and strengthening the lowlevel westerly and strong upward (downward) motion over the eastern (western) TP, thus supporting an earlier onset of the summer monsoon onset over the AS and India.

\subsection{Discussion}

The seesaw pattern of the diabatic heating over the TP exerts great impacts on the summer monsoon onset over South Asia, thus it is necessary to reveal the cause of the seesaw pattern of diabatic heating over the TP. Previous studies suggest that the Indian Ocean SST is a major forcing for the precipitation over the TP in May through affecting the summer monsoon over the BOB (Chen and You 2017; Zhao et al. 2018). This result is further verified in this work. The correlation coefficient between the diabatic heating seesaw pattern and the onset date of the BOB monsoon is of -0.35 , passing $95 \%$ confidence level. The precipitation anomaly over the southeastern TP, corresponding to the east center of diabatic heating, can be attributed to the transport of water vapor associated with anomalous BOB summer monsoon activities (Liu et al. 2019; 2017; Zhu et al. 2020). Besides, other factors including the SST in the North Atlantic (Cui et al. 2014; Yu et al. 2020) and the absorbing aerosol (Lau et al. 2006; Meehl et al. 2008) can also modulate the atmospheric heating over the TP in late spring, which is not addressed in this study.

In fact, the early onset of the BOB monsoon is often followed by the early monsoon onset over both the AS and India. The diabatic heating over the northeastern BOB due to deep convection after the $\mathrm{BOB}$ monsoon onset facilitates the SASM onset via modulating the SAH (Liu et al. 2014a). As mentioned in Sect. 4.2, the positive seesaw pattern of diabatic heating over the TP in May is in favor of the meridional temperature gradient reverse in the mid-upper troposphere over the AS and India, and such an influence is independent from ENSO, IPO and southern Indian Ocean dipole. Moreover, the difference in the diabatic heating seesaw pattern over the TP between the early and delayed SASM onset becomes obvious from the 5 th pentad before the monsoon onset (Fig. S3). Therefore, the diabatic heating over the TP and the onset of the BOB monsoon may influence the onset of the SASM simultaneously.

The interannual variation of the SASM onset is complex and receives influences from many other factors such as Madden-Julian Oscillation (Taraphdar et al. 2018), ENSO (Liu et al. 2014b), the timing of the SAH (Liu et al. 2013), anthropogenic aerosols (Bollasina et al. 2013, 2014), and black carbon (Mahmood and Li 2012). Therefore, the combined effect of these factors should be addressed in future studies. Moreover, a fully coupled model that includes atmosphere-land-ocean interactions is needed to explore a comprehensive mechanism for the SASM onset.

Supplementary Information The online version contains supplementary material available at https://doi.org/10.1007/s00382-022-06174-8.

Acknowledgements This research was jointly supported by the National Natural Science Foundation of China (Grant numbers 41725018 and 91937302).

Author contributions The study was conceived and designed by AD and DH. The numerical experiments based on CAM4.0 were conducted by PZ. The material and datasets were prepared by $\mathrm{DH}$. AD and $\mathrm{DH}$ contributed to the analysis of the data. The first draft of the manuscript was written by DH and all authors commented on previous versions of the manuscript. All authors read and approved the final manuscript.

Funding This study was funded by National Natural Science Foundation of China (Grant numbers 41725018 and 91937302).

Data availability The verification datasets are freely available at the following repositories: JRA-55: https://jra.kishou.go.jp/JRA-55/index_ en.html\#jra-55; ERSST.v5: https://psl.noaa.gov/data/gridded/data. noaa.ersst.v5.html; OLR: https://www.psl.noaa.gov/cgibin/db_search/ DBSearch.pl $?$ Dataset $=$ NOAA + Interpolated + OLR $\&$ Variable $=$ Out going + Longwave + Radiation; CMAP: https://www.psl.noaa.gov/data/ gridded/data.cmap.html. The CESM1.2.0 model is freely available at http://www.cesm.ucar.edu/models/cesm1.2/. 


\section{Declarations}

Conflict of interest The authors declare that they have no conflict of interests.

Open Access This article is licensed under a Creative Commons Attribution 4.0 International License, which permits use, sharing, adaptation, distribution and reproduction in any medium or format, as long as you give appropriate credit to the original author(s) and the source, provide a link to the Creative Commons licence, and indicate if changes were made. The images or other third party material in this article are included in the article's Creative Commons licence, unless indicated otherwise in a credit line to the material. If material is not included in the article's Creative Commons licence and your intended use is not permitted by statutory regulation or exceeds the permitted use, you will need to obtain permission directly from the copyright holder. To view a copy of this licence, visit http://creativecommons.org/licenses/by/4.0/.

\section{References}

Abe M, Hori M, Yasunari T, Kitoh A (2013) Effects of the Tibetan Plateau on the onset of the summer monsoon in South Asia: the role of the air-sea interaction. J Geophys Res Atmos 118:1760 1776. https://doi.org/10.1002/jgrd.50210

Aneesh S, Sijikumar S (2020) Existence of 'mini-break' like condition during early Indian monsoon onset years. Clim Dyn 54:2403-2418. https://doi.org/10.1007/s00382-020-05121-9

Athira UN, Abhilash S (2021) Ocean-atmosphere coupled processes in the tropical Indian Ocean region prior to Indian summer monsoon onset over Kerala. Clim Dyn 56:597-612. https://doi.org/ 10.1007/s00382-020-05499-6

Behera SK, Yamagata T (2001) Subtropical SST dipole events in the southern Indian Ocean. Geophys Res Lett 28:327-330. https:// doi.org/10.1029/2000gl011451

Bollasina MA, Ming Y, Ramaswamy V (2013) Earlier onset of the Indian monsoon in the late twentieth century: the role of anthropogenic aerosols. Geophys Res Lett 40:3715-3720. https://doi. org/10.1002/grl.50719

Bollasina MA, Ming Y, Ramaswamy V, Schwarzkopf MD, Naik V (2014) Contribution of local and remote anthropogenic aerosols to the twentieth century weakening of the South Asian Monsoon. Geophys Res Lett 41:680-687. https://doi.org/10.1002/ $2013 \mathrm{gl} 1058183$

Bombardi RJ, Moron V, Goodnight JS (2019) Detection, variability, and predictability of monsoon onset and withdrawal dates: a review. Int J Climatol 40:641-667. https://doi.org/10.1002/joc. 6264

Boos WR, Kuang Z (2010) Dominant control of the South Asian monsoon by orographic insulation versus plateau heating. Nature 463:218-222. https://doi.org/10.1038/nature08707

Cen S, Chen W, Chen S, Liu Y, Ma T (2020) Potential impact of atmospheric heating over East Europe on the zonal shift in the South Asian high: the role of the Silk Road teleconnection. Sci Rep 10:6543. https://doi.org/10.1038/s41598-020-63364-2

Cui Y, Duan A, Liu Y, Wu G (2014) Interannual variability of the spring atmospheric heat source over the Tibetan Plateau forced by the North Atlantic SSTA. Clim Dyn 45:1617-1634. https:// doi.org/10.1007/s00382-014-2417-9

Dai A, Li H, Sun Y, Hong L-C, Ho L, Chou C, Zhou T (2013) The relative roles of upper and lower tropospheric thermal contrasts and tropical influences in driving Asian summer monsoons. J
Gerontol Ser A Biol Med Sci 118:7024-7045. https://doi.org/ 10.1002/jgrd.50565

Deng M, Lu R, Chen W, Cao J (2016) Interannual variability of precipitation in May over the South Asian monsoonal region. Int J Climatol 36:1724-1732. https://doi.org/10.1002/joc.4454

Duan A, Liu S, Zhao Y, Gao K, Hu W (2018) Atmospheric heat source/sink dataset over the Tibetan Plateau based on satellite and routine meteorological observations. Big Earth Data 2:179-189. https://doi.org/10.1080/20964471.2018.1514143

Duan A, Hu D, Hu W, Zhang P (2020) Precursor effect of the Tibetan Plateau heating anomaly on the seasonal march of the East Asian summer monsoon precipitation. J Geophys Res Atmos. https://doi.org/10.1029/2020jd032948

Fasullo J, Webster P (2003) A hydrological definition of Indian Monsoon Onset and withdrawal. J Clim 16:3200-3211. https://doi. org/10.1175/1520-0442(2003)016<3200a:AHDOIM>2.0.CO;2

Gent PR, Danabasoglu G, Donner LJ, Holland MM, Hunke EC, Jayne SR, Lawrence DM, Neale RB, Rasch PJ, Vertenstein M, Worley PH, Yang Z-L, Zhang M (2011) The community climate system model version 4. J Clim 24:4973-4991. https://doi.org/10.1175/ 2011 jcli4083.1

Henley BJ, Gergis J, Karoly DJ, Power S, Kennedy J, Folland CK (2015) A Tripole Index for the interdecadal pacific oscillation. Clim Dyn 45:3077-3090. https://doi.org/10.1007/ s00382-015-2525-1

Huang B, Thorne PW, Banzon VF, Boyer T, Chepurin G, Lawrimore JH, Menne MJ, Smith TM, Vose RS, Zhang H-M (2017) Extended reconstructed sea surface temperature, version 5 (ERSSTv5): upgrades, validations, and intercomparisons. J Clim 30:81798205. https://doi.org/10.1175/JCLI-D-16-0836.1

Hurrell JW, Holland MM, Gent PR, Ghan S, Kay JE, Kushner PJ, Lamarque JF, Large WG, Lawrence D, Lindsay K, Lipscomb WH, Long MC, Mahowald N, Marsh DR, Neale RB, Rasch P, Vavrus S, Vertenstein M, Bader D, Collins WD, Hack JJ, Kiehl J, Marshall S (2013) The community earth system model: a framework for collaborative research. Bull Am Meteorol Soc 94:1339-1360. https://doi.org/10.1175/bams-d-12-00121.1

Kajikawa Y, Yasunari T, Yoshida S, Fujinami H (2012) Advanced Asian summer monsoon onset in recent decades. Geophys Res Lett. https://doi.org/10.1029/2011g1050540

Kobayashi S, Ota Y, Harada Y, Ebita A, Moriya M, Onoda H, Onogi K, Kamahori H, Kobayashi C, Endo H, Miyaoka K, Takahashi K (2015) The JRA-55 reanalysis: general specifications and basic characteristics. J Meteorol Soc Jpn Ser II 93:5-48. https://doi.org/ 10.2151/jmsj.2015-001

Lau KM, Kim MK, Kim KM (2006) Asian summer monsoon anomalies induced by aerosol direct forcing: the role of the Tibetan Plateau. Clim Dyn 26(7-8):855-864. https://doi.org/10.1007/ s00382-006-0114-z

Liebmann B, Smith CA (1996) Description of a complete (interpolated) outgoing longwave radiation dataset. Bull Am Meteorol Soc 77(6):1275-1277 (Retrieved from < Go to ISI>:// WOS:A1996VC04300013)

Liu B (2013) Formation and pattern variations of the South Asian High and their impacts on the Asian summer monsoon onset. Nanjing University of Information Science \& Technology, Nanjing

Liu Y, Ding Y (2008) Teleconnection between the Indian summer monsoon onset and the Meiyu over the Yangtze River Valley. Sci China, Ser D Earth Sci 51:1021-1035. https://doi.org/10.1007/ s11430-008-0073-9

Liu B, Wu G, Mao J, He J (2013) Genesis of the South Asian High and Its Impact on the Asian Summer Monsoon Onset. J Clim 26:2976-2991. https://doi.org/10.1175/jcli-d-12-00286.1

Liu B, Liu Y, Wu G, Yan J, He J, Ren S (2014a) Asian summer monsoon onset barrier and its formation mechanism. Clim Dyn 45:711-726. https://doi.org/10.1007/s00382-014-2296-0 
Liu B, Wu G, Ren R (2014b) Influences of ENSO on the vertical coupling of atmospheric circulation during the onset of South Asian summer monsoon. Clim Dyn 45:1859-1875. https://doi.org/10. 1007/s00382-014-2439-3

Liu Y, Wang Z, Zhuo H, Wu G (2017) Two types of summertime heating over Asian large-scale orography and excitation of potentialvorticity forcing II. Sensible heating over Tibetan-Iranian Plateau. Sci China Earth Sci 60:733-744. https://doi.org/10.1007/ s11430-016-9016-3

Liu Y, Chen H, Zhang G, Sun J, Wang H (2019) The advanced South Asian monsoon onset accelerates lake expansion over the Tibetan Plateau. Sci Bull 64:1486-1489. https://doi.org/10.1016/j.scib. 2019.08.011

Liu Y, Lu M, Yang H, Duan A, He B, Yang S, Wu G (2020) Landatmosphere-ocean coupling associated with the Tibetan Plateau and its climate impacts. Natl Sci Rev 7:534-552. https://doi.org/ $10.1093 / \mathrm{nsr} / \mathrm{nwaa} 011$

Liu B, He J (2015) Reviews on the dynamics of Asian summer monsoon. J Trop Meteorol 31:869-880. https://doi.org/10.16032/j. issn.1004-4965.2015.06.015

Mahmood R, Li S (2012) Delay in the onset of South Asian summer monsoon induced by local black carbon in an AGCM. Theor Appl Climatol 111:529-536. https://doi.org/10.1007/ s00704-012-0681-3

Mao J, Wu G (2006) Interannual variability in the onset of the summer monsoon over the Eastern Bay of Bengal. Theor Appl Climatol 89:155-170. https://doi.org/10.1007/s00704-006-0265-1

Mao JY, Chan JCL, Wu GX (2004) Relationship between the onset of the South China Sea summer monsoon and the structure of the Asian subtropical anticyclone. J Meteorol Soc Jpn 82:845-859. https://doi.org/10.2151/jmsj.2004.845

Mao JY, Wu GX, Liu YM (2002) Study on model variation of subtropical high and its mechanism during seasonal transition part III: thermodynamic diagnoses. Acta Meteorol Sin 60:647-659

Meehl GA, Arblaster JM, Collins WD (2008) Effects of black carbon aerosols on the Indian monsoon. J Clim 21(12):2869-2882. https://doi.org/10.1175/2007jcli1777.1

Meng W, Wu G (2000) Gearing between the indo-monsoon circulation/ Pacific-walker circulation and ENSO. Chin J Atmos Sci 15-25

Neena JM, Suhas E, Murtugudde R (2020) Boreal spring El Niño convective state and its impact on monsoon onset. Geophys Res Lett. https://doi.org/10.1029/2020gl090136

Pai D, Rajeevan M (2009) Summer monsoon onset over Kerala: new definition and prediction. J Earth Syst Sci 118:123-135. https:// doi.org/10.1007/s12040-009-0020-y

Prasad VS (2005) Onset and withdrawal of Indian summer monsoon. Geophys Res Lett. https://doi.org/10.1029/2005g1023269

Qian YF, Zhang Q, Yao YH, Zhang XH (2002) Seasonal variation and heat preference of the South Asia high. Adv Atmos Sci 19:821836. https://doi.org/10.1007/s00376-002-0047-3

Saha S, Saha K (1980) A hypothesis on onset, advance and withdrawal of the Indian summer monsoon. Pure Appl Geophys 118:10661075. https://doi.org/10.1007/BF01593050

Sun S, Ren R, Wu G (2017) Onset of the Bay of Bengal summer monsoon and the seasonal timing of ENSO's decay phase. Int J Climatol 37:4938-4948. https://doi.org/10.1002/joc.5134

Tamura T, Koike T (2010) Role of convective heating in the seasonal evolution of the Asian summer monsoon. J Geophys Res. https:// doi.org/10.1029/2009jd013418

Taniguchi K, Koike T (2006) Comparison of definitions of Indian summer monsoon onset: better representation of rapid transitions of atmospheric conditions. Geophys Res Lett. https://doi.org/10. 1029/2005g1024526

Tao S, Chen L (1987) A review of recent research on the East Asian summer monsoon in China. In: Chang CP, Krishnamurti TN (eds) Monsoon meteorology. Oxford University, Oxford, pp 60-92
Taraphdar S, Zhang F, Leung LR, Chen X, Pauluis OM (2018) MJO affects the monsoon onset timing over the Indian region. Geophys Res Lett 45:10011-10018. https://doi.org/10.1029/2018g1078804

Trenberth KE (1997) The definition of El Niño. Bull Am Meteorol Soc 78:2771-2778. https://doi.org/10.1175/1520-0477(1997)078\% 3c2771:Tdoeno\%3e2.0.Co;2

Vinayachandran PN, Shankar D, Kurian J, Durand F, Shenoi SSC (2007) Arabian Sea mini warm pool and the monsoon onset vortex. Curr Sci 93:203-214

Wang B, Ho L (2002) Rainy season of the Asian-Pacific summer monsoon. J Clim. https://doi.org/10.1175/1520-0442(2002)015\% 3c0386:Rsotap\%3e2.0.Co;2

Wang B, Ding Q, Joseph PV (2009) Objective definition of the Indian Summer monsoon onset. J Clim 22:3303-3316. https://doi.org/ 10.1175/2008jcli2675.1

Wang Z, Duan A, Yang S (2018) Potential regulation on the climatic effect of Tibetan Plateau heating by tropical air-sea coupling in regional models. Clim Dyn 52:1685-1694. https://doi.org/10. 1007/s00382-018-4218-z

Webster P, Yang S (1992a) Monsoon and ENSO: selectively interactive systems. Q J R Meteorol Soc 118:877-926. https://doi.org/ 10.1002/qj.49711850705

Wei W, Wu Y, Yang S, Zhou W (2019) Role of the South Asian High in the onset process of the Asian Summer Monsoon during Springto-Summer Transition. Atmosphere. https://doi.org/10.3390/atmos 10050239

Wei W, Zhang R, Wen M, Rong X, Li T (2014) Impact of Indian summer monsoon on the South Asian High and its influence on summer rainfall over China. Clim Dyn 43:1257-1269. https://doi.org/ 10.1007/s00382-013-1938-y

Wu R, Hu W (2015) Air-sea relationship associated with precipitation anomaly changes and mean precipitation anomaly over the South China Sea and the Arabian Sea during the Spring to Summer Transition. J Clim 28:7161-7181. https://doi.org/10.1175/ jcli-d-15-0136.1

Wu G, Zhang Y (1998) Tibetan Plateau forcing and the timing of the monsoon onset over South Asia and the South China Sea. Mon Weather Rev 126:913-927. https://doi.org/10.1175/15200493(1998)126\%3c0913:Tpfatt\%3e2.0.Co;2

Wu G, Liu Y, Wang T, Wan R, Liu X, Li W, Wang Z, Zhang Q, Duan A, Liang X (2007) The influence of mechanical and thermal forcing by the Tibetan Plateau on Asian climate. J Hydrometeorol 8:770-789. https://doi.org/10.1175/jhm609.1

Wu G, Guan Y, Wang T, Liu Y, Yan J, Mao J (2010) Vortex genesis over the Bay of Bengal in spring and its role in the onset of the Asian Summer Monsoon. Sci China Earth Sci 54:1-9. https://doi. org/10.1007/s11430-010-4125-6

Wu G, Liu Y, He B, Bao Q, Duan A, Jin F-F (2012) Thermal controls on the Asian Summer Monsoon. Sci Rep 2:404. https://doi.org/ 10.1038/srep00404

Wu G, He B, Liu Y, Bao Q, Ren R (2015) Location and variation of the summertime upper-troposphere temperature maximum over South Asia. Clim Dyn 45:2757-2774. https://doi.org/10.1007/ s00382-015-2506-4

Xavier PK, Marzin C, Goswami BN (2007) An objective definition of the Indian summer monsoon season and a new perspective on the ENSO-monsoon relationship. Q J R Meteorol Soc 133:749-764. https://doi.org/10.1002/qj.45

Xie P, Arkin PA (1997) Global precipitation: A 17-year monthly analysis based on gauge observations, satellite estimates, and numerical model outputs. Bull Amer Meteor Soc 78:2539-2558. https://doi. org/10.1175/1520-0477(1997)078\%3c2539:GPAYMA\%3e2.0. $\mathrm{CO} ; 2$

Xing N, Li J, Wang L (2015) Effect of the early and late onset of summer monsoon over the Bay of Bengal on Asian precipitation 
in May. Clim Dyn 47:1961-1970. https://doi.org/10.1007/ s00382-015-2944-z

Yanai M, Esbensen S, Chu J-H (1973) Determination of bulk properties of tropical cloud clusters from large-scale heat and moisture budgets. J Atmos Sci 30:611-627. https://doi.org/10.1175/15200469(1973)030\%3c0611:DOBPOT\%3e2.0.CO;2

Yang K, Qin J, Guo X, Zhou D, Ma Y (2009) Method development for estimating sensible heat flux over the Tibetan Plateau from CMA data. J Appl Meteorol Climatol 48:2474-2486. https://doi.org/10. 1175/2009JAMC2167.1

Yasunari T (1991) The Monsoon year-a new concept of the climatic year in the tropics. Bull Am Meteorol Soc 72:1331-1338. https:// doi.org/10.1175/1520-0477\%281991\%29072\%3c1331:Tmynco\% 3e2.0.Co; 2

Ye D, Gao Y (1979) The meteorology of the Qinghai-Xizang (Tibet) Plateau. Science Press, Beijing (In Chinese)

Yu W, Li K, Shi J, Lin L, Wang H, LiU Y (2015) The onset of the monsoon over the Bay of Bengal: the year-to-year variations. Atmos Ocean Sci Lett 5:342-347. https://doi.org/10.1080/16742 834.2012.11447011

Yu W, Liu Y, Yang X-Q, Wu G, He B, Li J, Bao Q (2020) Impact of North Atlantic SST and Tibetan Plateau forcing on seasonal transition of springtime South Asian monsoon circulation. Clim Dyn. https://doi.org/10.1007/s00382-020-05491-0

Zhang Y, Li Z, Liu B (2015) Interannual variability of surface sensible heating over the Tibetan Plateau in Boreal Spring and its influence on the onset time of the Indian Summer Monsoon. Chin J Atmos Sci 39:1059-1072

Zhang W, Zhou T, Zhang L (2017) Wetting and greening Tibetan Plateau in early summer in recent decades. J Geophys Res Atmos 122:5808-5822. https://doi.org/10.1002/2017jd026468

Zhang R (2001) Relations of water vapor transport from Indian monsoon with that over East Asia and the summer rainfall in China. Adv Atmos Sci 18:1005-1017. https://doi.org/10.1007/BF034 03519

Zhao Y, Duan A, Wu G (2018) Interannual variability of Late-spring circulation and diabatic heating over the Tibetan Plateau associated with Indian Ocean forcing. Adv Atmos Sci 35:927-941. https://doi.org/10.1007/s00376-018-7217-4

Zhou F, Ren H-L, Hu Z-Z, Liu M-H, Wu J, Liu C-Z (2020) Seasonal predictability of primary East Asian summer circulation patterns by three operational climate prediction models. Q J R Meteorol Soc 146:629-646. https://doi.org/10.1002/qj.3697

Zhu Y (2012) Variations of the summer Somali and Australia crossequatorial flows and the implications for the Asian summer monsoon. Adv Atmos Sci 29:509-518. https://doi.org/10.1007/ s00376-011-1120-6

Zhu Y, Sang Y, Chen D, Sivakumar B, Li D (2020) Effects of the South Asian summer monsoon anomaly on interannual variations in precipitation over the South-Central Tibetan Plateau. Environ Res Lett. https://doi.org/10.1088/1748-9326/abc71b

\section{Uncategorized References}

Chen X, You Q (2017) Effect of Indian Ocean SST on Tibetan Plateau Precipitation in the Early Rainy Season. J Clim 30:8973-8985. https://doi.org/10.1175/jcli-d-16-0814.1

Chen LX, Reiter ER, Feng ZQ (1985) The atmospheric heat source over the Tibetan Plateau: May-August 1979. Mon Weather Rev 113:1771-1790. https://doi.org/10.1175/1520-0493(1985)113\% 3c1771:Tahsot\%3e2.0.Co;2

Luo H, Yanai M (1984) The large-scale circulation and heat sources over the Tibetan Plateau and surrounding areas during the early summer of 1979. Part II: heat and moisture budgets. Mon Weather Rev 112:966-989. https://doi.org/10.1175/1520-0493(1984)112\% 3c0966:Tlscah\%3e2.0.Co;2

Neale RB, Chen C-C, Gettelman A, Lauritzen PH, Park S, Williamson DL, Conley AJ, Garcia R, Kinnison D, Lamarque J-F (2010) Description of the NCAR community atmosphere model (CAM 5.0). NCAR Tech. Note NCAR/TN-486+ STR 1, pp 1-12

Sun R, Duan A, Chen L, Li Y, Xie Z, Zhao Y (2019) Interannual variability of the North Pacific mixed layer associated with the Spring Tibetan Plateau thermal forcing. J Clim 32:3109-3130. https://doi. org/10.1175/jcli-d-18-0577.1

Wang M, Zhou S, Duan A (2011) Trend in the atmospheric heat source over the central and eastern Tibetan Plateau during recent decades: comparison of observations and reanalysis data. Chin Sci Bull 57:548-557. https://doi.org/10.1007/s11434-011-4838-8

Zhao Y, Duan A, Wu G (2021) Opposite responses of the Indian Ocean to the thermal forcing of the Tibetan Plateau before and after the onset of the South Asian monsoon. J Clim. https://doi.org/10. 1175/jcli-d-20-0982.1

Publisher's Note Springer Nature remains neutral with regard to jurisdictional claims in published maps and institutional affiliations. 